\title{
Müller Cell-Localized G-Protein-Coupled Receptor 81 (Hydroxycarboxylic Acid Receptor 1) Regulates Inner Retinal Vasculature via Norrin/Wnt Pathways
}

Ankush Madaan, ${ }^{\dagger \dagger}$ Prabhas Chaudhari, ${ }^{*}$ Mathieu Nadeau-Valleee, ${ }^{\star \S}$ David Hamel, ${ }^{*}$ Tang Zhu, ${ }^{*}$ Grant Mitchell, ${ }^{*}$ Mark Samuels, ${ }^{*}$ Sheetal Pundir, ${ }^{*}$ Rabah Dabouz, ${ }^{*}$ Colin Wayne Howe Cheng, ${ }^{\dagger}$ Mohammad A. Mohammad Nezhady, ${ }^{*}$ Jean-Sébastien Joyal, ${ }^{*}$ José Carlos Rivera, ${ }^{* \pi}$ and Sylvain Chemtob ${ }^{* \dagger \S \pi}$

From the Departments of Pediatrics, Ophthalmology and Pharmacology, * Centre Hospitalier Universitaire Sainte-Justine Research Center, Montréal, Quebec; the Departments of Pharmacology and Therapeutics ${ }^{\dagger}$ and Experimental Medicine, ${ }^{\ddagger}$ McGill University, Montréal, Quebec; the Department of Pharmacology, ${ }^{\S}$ Université de Montréal, Montréal, Quebec; and the Research Center, ${ }^{\Uparrow}$ Maisonneuve-Rosemont Hospital, Montréal, Quebec, Canada

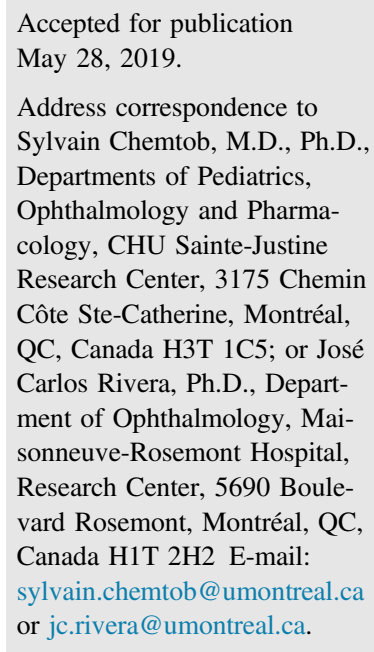

\begin{abstract}
Ischemic retinopathies are characterized by a progressive microvascular degeneration followed by a postischemic aberrant neovascularization. To reinstate vascular supply and metabolic equilibrium to the ischemic tissue during ischemic retinopathies, a dysregulated production of growth factors and metabolic intermediates occurs, promoting retinal angiogenesis. Glycolysis-derived lactate, highly produced during ischemic conditions, has been associated with tumor angiogenesis and wound healing. Lactate exerts its biological effects via G-protein-coupled receptor 81 (GPR81) in several tissues; however, its physiological functions and mechanisms of action in the retina remain poorly understood. Herein, we show that GPR81, localized predominantly in Müller cells, governs deep vascular complex formation during development and in ischemic retinopathy. Lactate-stimulated GPR81 Müller cells produce numerous angiogenic factors, including Wnt ligands and particularly Norrin, which contributes significantly in triggering inner retinal blood vessel formation. Conversely, GPR81-null mice retina shows reduced inner vascular network formation associated with low levels of Norrin (and Wnt ligands). Lactate accumulation during ischemic retinopathy selectively activates GPR81-extracellular signalregulated kinase $1 / 2-$ Norrin signaling to accelerate inner retinal vascularization in wild-type animals, but not in the retina of GPR81-null mice. Altogether, we reveal that lactate via GPR81-Norrin participates in inner vascular network development and in restoration of the vasculature in response to injury. These findings suggest a new potential therapeutic target to alleviate ischemic diseases. (Am J Pathol 2019, 189: 1878-1896; https://doi.org/10.1016/j.ajpath.2019.05.016)
\end{abstract}

Ischemic retinopathies, such as retinopathy of prematurity and diabetic retinopathy, are characterized by an initial phase of microvascular degeneration, which is usually most pronounced in the deep vascular network ${ }^{1}$ and is preceded by a secondary phase of exaggerated aberrant preretinal neovascularization. $^{2-6}$ The initial inner retinal vessel depletion leads to retinal hypoxia, ${ }^{7,8}$ which results in damage to retinal neurons, as has been described experimentally
Supported by Canadian Institutes of Health Research (CIHR) grant FRN12532 (S.C.). A.M. was a recipient of the CIHR Drug Design Training Program; Systems Biology Training Program; Vision Research Network; and Provost Graduate Fellowship (Department of Pharmacology and Therapeutics, McGill University). S.C. holds a Canada Research Chair (Vision Science) and the Leopoldine Wolfe Chair in translational research in age-related macular degeneration.

Disclosures: None declared. 
and clinically ${ }^{9,10}$; this observation is consistent with evidence that prompts postischemia revascularization lessens adverse outcome. ${ }^{11-19}$ Hence, to diminish the duration of intraretinal ischemia, it is requisite to determine the factors that govern the development of the deep intraretinal vascular network. Notwithstanding the paramount and widespread role of hypoxia-triggered vascular endothelial growth factor in neovascularization, not surprisingly other factors also partake in this process. ${ }^{2,4}$ Of interest, intermediates of carbohydrate metabolism significantly affected by hypoxic ischemia have generally been overlooked. For instance, the Krebs cycle metabolite succinate has been shown by us to exert an important role in regulating retinal angiogenesis. ${ }^{20}$ Specifically, G-protein-coupled receptor 91 (GPR91), present on retinal ganglion cells (RGCs), governs the release of numerous angiogenic factors implicated mostly in the development of the superficial retinal vasculature. ${ }^{20}$

It has been proposed that the deep retinal vascular network is formed in response to a hypoxic state that triggers the release of factors from the pan-retinal Müller cells. ${ }^{21,22}$ It is now established that Norrin, specifically secreted by Müller cells, guides deep vascular complex development. ${ }^{23}$ Norrin exerts it vasoproliferative effect by binding with high affinity to a receptor, Frizzled-4 (Fzd4), which interacts with its coreceptor low density lipoprotein receptor-related protein 5 (Lrp5) and the transmembrane polypeptide, tetraspanin 12 (Tspan12), present on the surface membrane of vascular cells. ${ }^{24,25}$ Mutation in any of these genes encoding these four proteins leads to insufficient inner retinal vascular development. ${ }^{25}$ Norrin has been shown to be involved in promoting vascular regrowth after oxygen-induced vessel loss and suppresses ischemic retinopathy. ${ }^{26}$ However, to date, the factors that control Norrin expression in the retina are still not well known.

Lactate is a glycolysis-derived metabolite, abundantly generated by the highly glycolytic Müller cells in the retina. ${ }^{27}$ Lactate, produced by Müller cells, can act in an autocrine manner, be exported to ganglion cells and photoreceptor as fuel, or be exchanged in the retinal blood vessels. ${ }^{28,29}$ In the circumstance of reduced tissue oxygenation or an increased metabolic rate, lactate rapidly increases before any changes in downstream Krebs cycle activity. ${ }^{30,31}$ Interestingly, lactate is not simply a glycolytic end product, but its increases have been associated with angiogenesis in tumors and wound healing, ${ }^{32-34}$ and vasodilatation in the inner retina, ${ }^{35}$ suggesting a link between capillary function and tissue metabolic needs. Furthermore, a neuroprotective role for exogenous lactate in pathologic situations, such as diabetes and cerebral ischemia, has been documented. ${ }^{36-38}$ Lactate was recently found to exert its biological effects specifically via GPR81 [alias hydroxycarboxylic acid receptor (HCA1 or HCAR1)], mostly expressed in fat, as well as in the central nervous system. ${ }^{39-41}$ GPR81 has been demonstrated to be implicated in several functions, including antilipolytic effects in the adipose tissue, ${ }^{39,42}$ protection against ischemic brain injury, ${ }^{43}$ cancer cell survival, ${ }^{44}$ attenuation of inflammation, ${ }^{45,46}$ and, recently, angiogenesis in breast tumors. ${ }^{47}$ However, its physiological functions in governing neuroretinal vascularization during development and ischemic retinopathy are not known. Herein, we propose that lactate, acting through its GPR81 receptor present in retina, is implicated in the regulation of retinal angiogenesis. Our findings reveal, for the first time, that lactate-induced Norrin production by activating GPR81 receptor present in Müller cells regulates deep vascular complex development and promotes revascularization in ischemic retinopathy.

\section{Materials and Methods}

\section{Animals}

The use of mice for this study was first approved by the Animal Care Committee of Sainte-Justine's Hospital (Montréal, Canada) following the principles of the Guide for the Care and Use of Experimental Animals developed by the Canadian Council on Animal Care. C57BL/6J mice were obtained from Charles River Inc. (Montreal, Canada) with pups at postnatal day (P) 2 and were allowed to acclimatize for 2 days before experiments. The animals were maintained on standard laboratory chow under a 12:12 light/dark cycle and allowed free access to chow and water. GPR81 ${ }^{-1-}$ mice were obtained from Lexicon Pharmaceuticals (The Woodlands, TX) and were used following the same aforementioned guidelines. The $\mathrm{GPR} 81^{-1-}$ mice were backcrossed with adult $\mathrm{C} 57 \mathrm{BL} / 6 \mathrm{~J}$ mice to obtain a pure C57/BL suitable for oxygen-induced retinopathy (OIR) experiments. The transmembrane domain 2 of mice GPR81 coding region (100 bp) is replaced by a 4-kb IRESlacZ-neo cassette. All experimental protocols were approved by the Animal Care Committee of Sainte-Justine's Hospital.

\section{Chemical Data}

Lactate was purchased from Sigma-Aldrich (L1750; Oakville, Canada).

\section{OIR Mice Model}

The vaso-obliteration and neovascularization models used in this study were designed on the basis of a well-established mice model of retinopathy of prematurity-the OIR model. ${ }^{48}$ C57BL/6J mice were placed with an adoptive breastfeeding CD1 mother at P5 to avoid cannibalism in hyperoxia compared with the C57BL/6J mothers. These litters were placed in a hyperoxic chamber with $75 \% \pm 2 \%$ oxygen from P7 to P12. As mothers are more vulnerable to the toxic effects of oxygen, they were exchanged between normoxic and hyperoxic cages every day. The litters of mice were returned to normoxia or $21 \% \mathrm{O}_{2} 5$ days later, on P12. 
The mice were anesthetized with isoflurane (2\%) and sacrificed by decapitation. The eyes from P12 pups were enucleated, and retinas were dissected to evaluate vasoobliteration in retinal flat mounts. At P17, the mice were sacrificed, and eyes were enucleated to analyze preretinal neovascularization. The weight of mice was considered to exclude underdeveloped mice, thereby eliminating the difference in weight gain as a variable factor. ${ }^{49}$ Control animals were maintained in room air $\left(21 \% \mathrm{O}_{2}\right)$. All other conditions (eg, light exposure, temperature, and feeding) were similar for both treatment groups.

\section{Retinal Flat Mounts}

Mice eyes were collected and processed for retinal flat mounts, as in previously published studies. ${ }^{50,51}$ Briefly, eyes were fixed in $4 \%$ paraformaldehyde and then retinas were isolated and incubated overnight at $4{ }^{\circ} \mathrm{C}$ in a solution containing $1 \%$ Triton $\mathrm{X}-100$ and $1 \mathrm{mmol} / \mathrm{L} \mathrm{CaCl} \mathrm{Cl}_{2} /$ phosphatebuffered saline (PBS) and tetramethylrhodamine isothiocyanate-conjugated lectin endothelial cell marker Bandeiraea simplicifolia (1:100; Sigma-Aldrich, St. Louis, MO). Retinas were mounted and imaged under a confocal microscope (Olympus, Richmond Hill, Canada) using a $30 \times$ objective or a Zeiss AxiObserver Z1 motorized inverted microscope (Zeiss, San Diego, CA) using a 10× objective. Retinal vascular densities were calculated using the AngioTool software version 0.5 (National Cancer Institute, Bethesda, MD). ${ }^{52}$ Vascular density in study groups was normalized with that of untreated groups raised in $21 \%$ $\mathrm{O}_{2}$. Vaso-obliterated areas were assessed as the retinal area devoid of vasculature/the total retinal area. Neovascularization was analyzed using the SWIFT-NV method, ${ }^{53}$ which consists of a set of macros that was developed to quantify all of the pixels represented by neovascular tufts and clusters, but not normal vessels in lectinstained retinal whole mounts.

\section{Electroretinography}

Electroretinograms (ERGs) were recorded from wild-type (WT) and age-matched knockout mice (6 months old) on an Espion ERG Diagnosys machine and a ColorDome Ganzfeld stimulator (Diagnosys LLC, Lowell, MA). Mice were dark adapted overnight and anesthetized intraperitoneally with a mixture of $100 \mathrm{mg} / \mathrm{kg}$ ketamine and $20 \mathrm{mg} / \mathrm{kg}$ xylazine solution. Pupils were dilated using atropine and phenylephrine. A drop of methylcellulose was placed onto the corneal surface to prevent corneal dehydration. Mouse body temperature was maintained at $37^{\circ} \mathrm{C}$ using a heated water pad. The protocol for the analysis of retinal function was similar to the version of the human ERG standard by the International Standard for Clinical Electrophysiology of Vision.

Flash ERGs were measured using a gold wire corneal electrode, and the electrodes were placed onto the surface of the cornea. A needle electrode on the forehead served as a reference electrode, and a needle electrode near the base of the tail served as ground. Scotopic responses were simultaneously recorded from both eyes of the dark-adapted animals at the following increasing light intensities: 0.01 , 3.0 , and $10.0 \mathrm{~cd}$-seconds $/ \mathrm{m}^{2}$. Photopic responses were recorded at the light intensity of $3.0 \mathrm{~cd}$-seconds $/ \mathrm{m}^{2}$ in the presence of a rod-saturating background. Ten waveform responses were averaged in each step. All procedures were performed in a dark room under dim red-light illumination. The amplitude and latency of major ERG components were measured with Espion software version 4.0 (Diagnosys LLC). The ERG a-wave amplitudes were measured from the baseline to the negative peak, and the b-wave amplitude was measured from the trough of the a-wave to the peak of the positive wave.

\section{Lv Production and Intravitreal Injection}

Lentivirus (Lv) was generated by transiently transfecting lentivector and packaging vectors into 293FT cells (Invitrogen, Carlsbad, CA), as previously described..$^{54}$ Five different shRNA sequences were used against Gpr81 (RMM4534-EG243270; Dharmacon, Lafayette, $\mathrm{CO}$ ), and the most effective were selected [442: $5^{\prime}$ TTGACCGAGCAGAACAAGATG- $3^{\prime}$ (forward) and $5^{\prime}$ CATCTTGTTCTGCTCGGTCAA- $3^{\prime}$ (reverse); and 448: $5^{\prime}$ AAGATGACCAAAGTCCAGAGG-3' (forward) and $5^{\prime}$ CCTCTGGACTTTGGTCATCTT-3' (reverse)]. Separately, $\mathrm{Lv}$ Norrin or Lv green fluorescence protein (GFP; under cytomegalovirus promoter) was also injected in GPR81-null animals. In vivo infections were performed in mice at $\mathrm{P} 4$ with a single intravitreal injection. Briefly, mice were steadily anesthetized with an isoflurane mask. After anesthesia, 1 to $2 \mu \mathrm{L}$ of vehicle, $\mathrm{Lv}$ scrambled or $\mathrm{Lv}$ short hairpin (sh)GPR81, was injected intravitreally in the vitreous humor. Lv was allowed to infect the retina for 72 hours. The vascular density of retinas was evaluated by retinal flat mounts and cryosections, as described above.

\section{Intravitreal Injections of Lactate}

On P5 or P7, mice pups were anesthetized with isoflurane $(2 \%)$ and intravitreally injected with $10 \mathrm{mmol} / \mathrm{L}$ lactate buffered to $\mathrm{pH} \approx 7.3$ (to avoid effects induced simply by low $\mathrm{pH}$ of lactic acid) or sterile PBS as control (final intravitreal concentration based on estimated eye volume) using a Hamilton syringe (Hamilton Company, Franklin, MA) with glass capillaries of approximately 60 gauge (total volume injected, approximately $1 \mu \mathrm{L}$ ). The concentration of lactate is consistent with that observed in pathophysiologic settings ( 5 to $20 \mathrm{mmol} / \mathrm{L}$ ). ${ }^{55}$ Forty-eight hours after the administration of lactate, the animals were euthanized, the eyes were removed, retinal flat mounts were stained by the lectin staining technique described above, and vascular density was evaluated using ImageJ software version $1.51 \mathrm{~d}$ (NIH, Bethesda, MD; https://imagej.nih.gov/ij). 

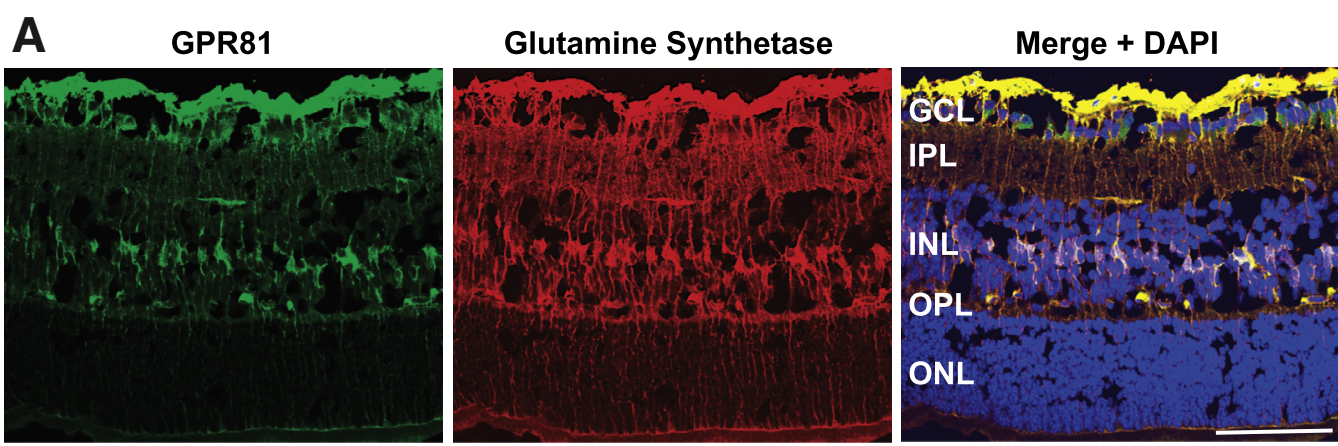

B
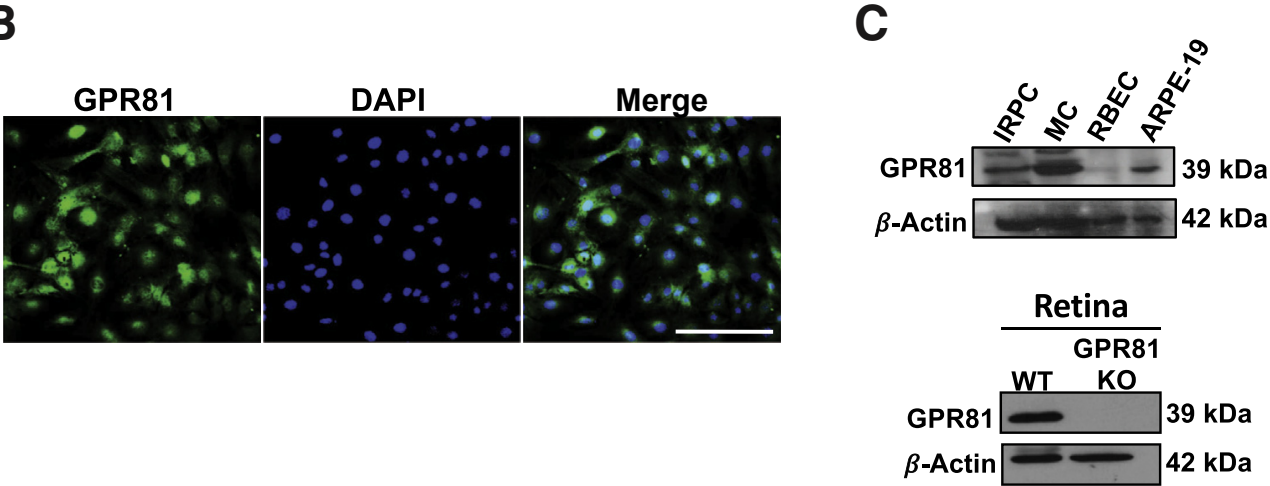

D

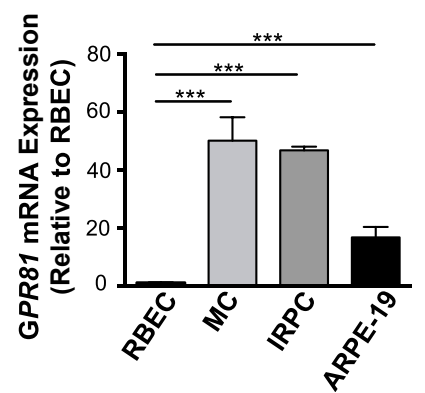

Figure 1 Lactate receptor GPR81 localization in mouse retina. A: Representative confocal images of retinal sagittal sections from P17 wild-type (WT) mice showing colocalization of GPR81 immunoreactivity (red) with the specific Müller cell (MC) marker glutamine synthetase (green) in yellow (merged image; nuclei were counterstained with DAPI in blue). B: GPR81 immunoreactivity is also strongly corroborated in primary Müller cells extracted from P8 WT mice. C: Western blot analysis in homogenates from immortalized retinal precursor cells (IRPCs), MCs, endothelial cells [rat brain endothelial cells (RBECs)], and adult retinal pigment epithelium cell line-19 (ARPE-19) showing GPR81 protein (39-kDa) expression. Immunoreactivity to GPR81 was also present in retinal homogenates from WT mice, but absent in retinas of GPR81-null mice. $\beta$-Actin ( $42 \mathrm{kDa}$ ) was used as an internal control. D: Real-time quantitative PCR analysis shows abundant GPR81 mRNA expression in Müller glia and IRPCs, but lower and minimal expression in retinal pigment epithelium cells (ARPE-19) and endothelial cells (RBECs), respectively. Data are expressed as means \pm SEM. $n=3$ (C and $\mathbf{D}$ ). ${ }^{* \star *} P<0.001$ (by one-way analysis of variance with a Dunnett postanalysis compared with RBECs set at 1). Scale bars: $50 \mu \mathrm{m}(\mathbf{A}) ; 100 \mu \mathrm{m}(\mathbf{B}) . \mathrm{GCL}$, ganglion cell layer; INL, inner nuclear layer; IPL, inner plexiform layer; $\mathrm{K} 0$, knockout; $\mathrm{ONL}$, outer nuclear layer; $\mathrm{OPL}$, outer plexiform layer.

\section{Cell Culture}

Primary Müller cells from WT and GPR81 ${ }^{-1-}$ mice (extracted and characterized, as described before $^{56}$ ) and immortalized retinal precursor cells (originally called RGC- $5^{57}$ ) were cultured in Dulbecco's modified Eagle's medium growth medium supplemented with $10 \%$ serum, 50 $\mathrm{U} / \mathrm{mL}$ penicillin, and $50 \mathrm{mg} / \mathrm{mL}$ streptomycin. Cells were propagated in regular conditions $\left(37^{\circ} \mathrm{C}, 5 \% \mathrm{CO}_{2}\right)$. For in vitro experiments, cells (serum starved overnight) from WT or GPR $81^{-I-}$ mice were treated with $10 \mathrm{mmol} / \mathrm{L}$ lactate (pH balanced), consistent with effective concentrations used in young subjects, ${ }^{46}$ and were pretreated with $2 \mu \mathrm{mol} / \mathrm{L}$ extracellular signal-regulated kinase (Erk)1/2-specific inhibitor U0126 for 1 hour, followed by treatment with lactate or PBS for 8 hours. Cells and tissues were then collected in RiboZol (AMRESCO, LLC, Solon, OH) and stored at $-80^{\circ} \mathrm{C}$ for mRNA extraction and real-time quantitative PCR.

\section{RNA Extraction and Real-Time Quantitative PCR}

RNA from retinal tissues or cultured cells was extracted according to manufacturer's protocol. Cells were pretreated with Lv scrambled or Lv shGPR81 for 72 hours. Total RNA was 
A

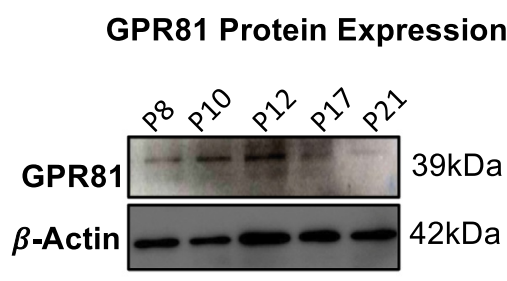

B

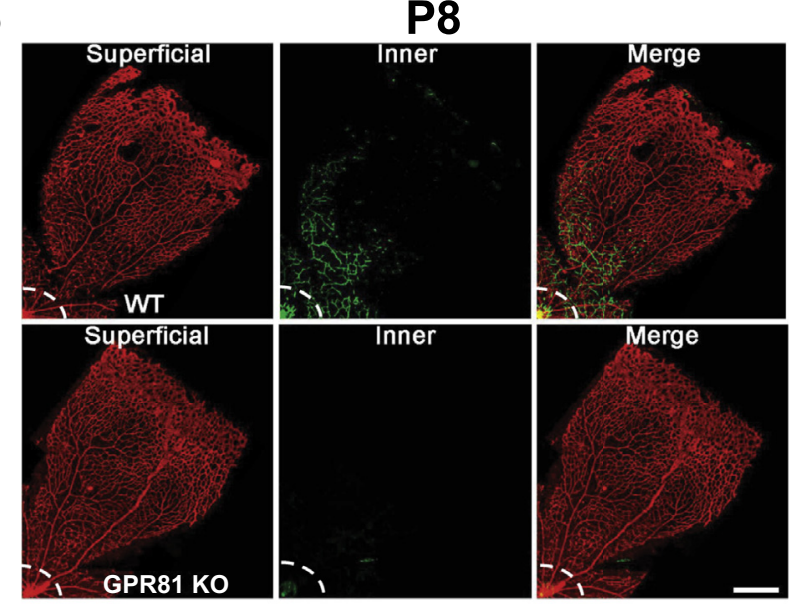

\section{P14}

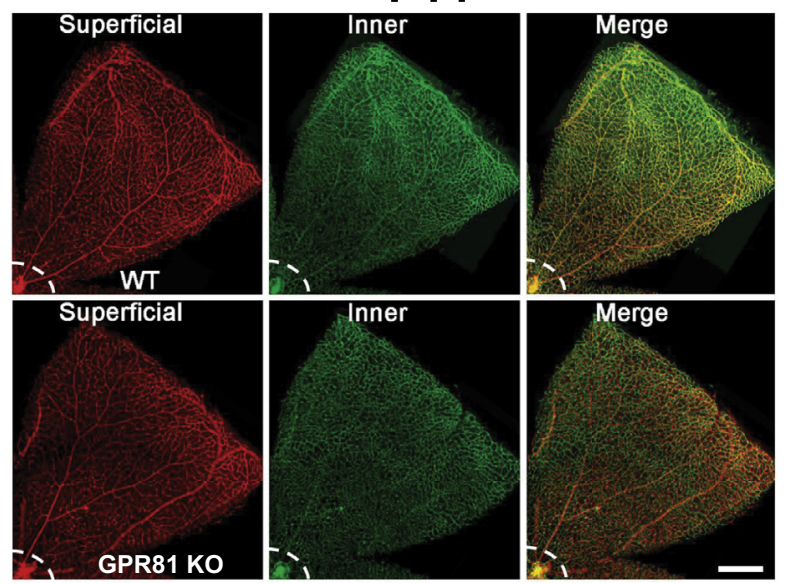

C

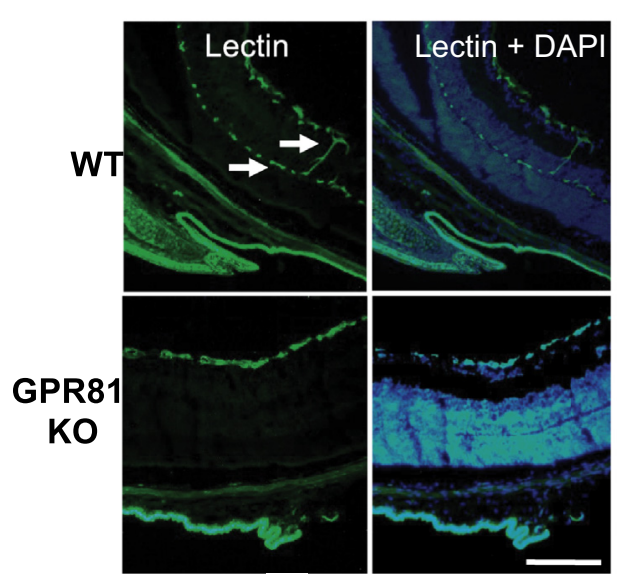

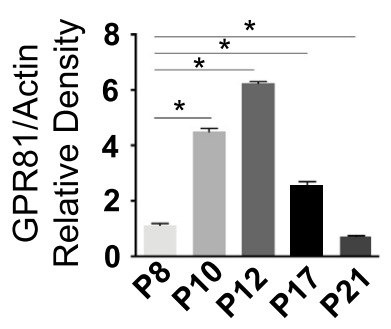
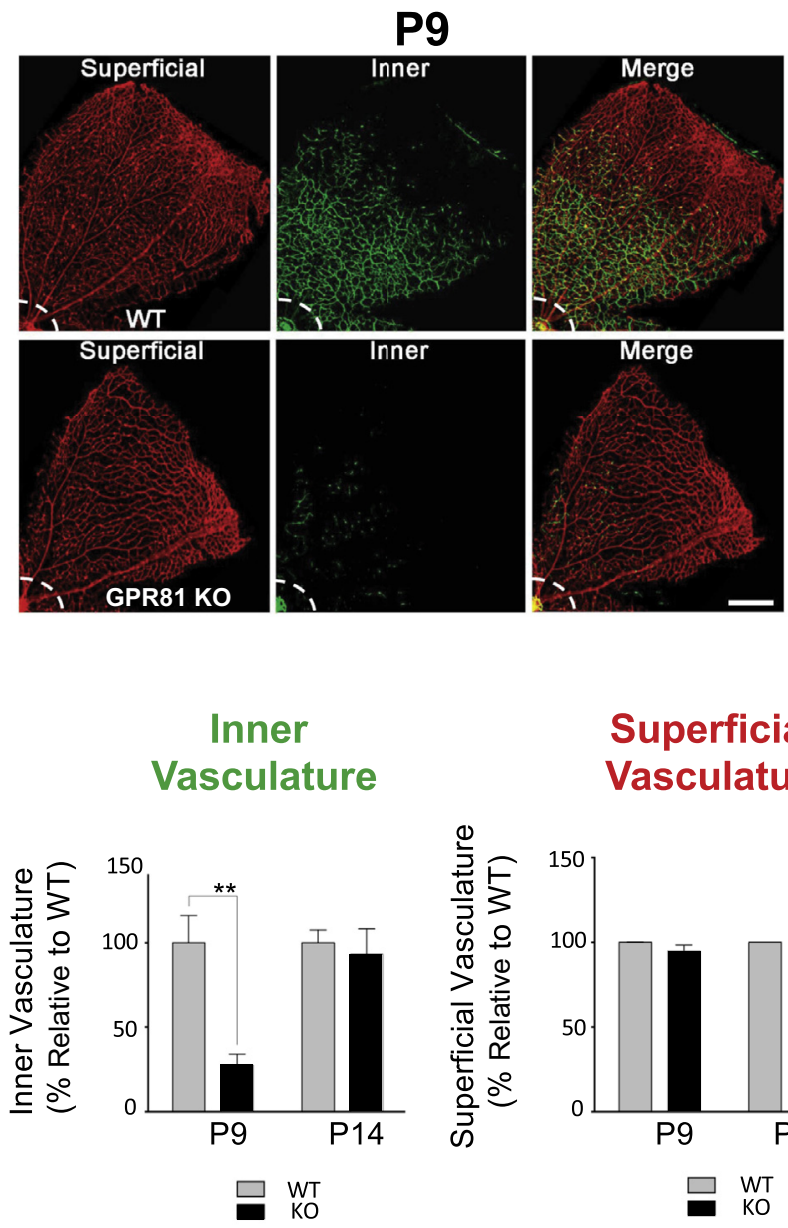

\section{Superficial} Vasculature
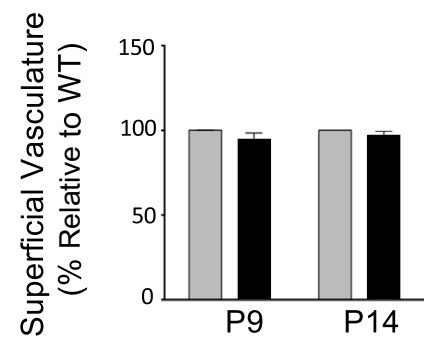

曰 $\mathrm{WO}_{\mathrm{KO}}^{\mathrm{PT}}$
D

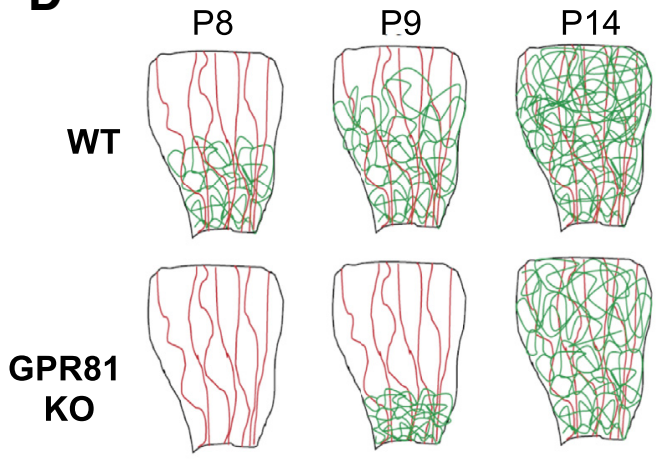

Inner Retinal Vasculature

Superficial Vasculature 
isolated with an RNase TM mini kit (Qiagen, Germantown, MD). The RNA concentration and integrity were measured with a NanoDrop 1000 spectrophotometer (Thermo Fisher Scientific, Wilmington, DE). RNA (500 ng) was used to synthesize cDNA using iScript Reverse Transcription SuperMix (Bio-Rad, Hercules, CA). Primers were designed using the National Center for Biotechnology Information's Primer Blast: GPR81, 5'-CCGGTTCATCATGGTGGTGGCT-3' (forward) and 5'CTCTTCTGACCTCCGCGTCTTC-3' (reverse); Lrp5, 5'AAGGGTGCTGTGTACTGGAC-3' (forward) and $5^{\prime}$ AGAAGAGAACCTTACGGGACG-3' (reverse); $F z d 4,5^{\prime}$ TTCCTTTGTTCGGTTTATGTGCC-3 $3^{\prime}$ (forward) and $5^{\prime}$ CTCTCAGGACTGGTTCACAGC-3' (reverse); TSPAN12, $5^{\prime}$-CCCCGTCATGATTGCTGTCT-3' (forward) and $5^{\prime}$ CCTCCTGCTCGTATGTCCAC-3' (reverse); Norrin, 5'CGCTGCATGAGACACCATTAT-3' (forward) and $5^{\prime}$ CTCAGAGCGTGATGCCTGG-3' (reverse); Wnt3, 5'GGTTCGTGCGGATGGGTGGG-3' (forward) and $5^{\prime}$ GGGGCCAGATGGGAGCTGGA-3' (reverse); Wnt7, 5'CACTTGTGGTCTCAGGGGTT- $3^{\prime}$ (forward) and $5^{\prime}$ GCATCTGAGTTTCACCAGCA-3' (reverse); Wnt10, $5^{\prime}$ GCTCAACGCCAACACAGTG-3' (forward) and $5^{\prime}$ CGAAAACCTCGGCTGAAGATG-3' (reverse); plasmalemma vesicle-associated protein (PLVAP), 5' CGTCAAGGCCAAGTCGCT-3' (forward) and 5'-CATCCACAGGTGGGCGATT-3' (reverse); and Claudin-5, 5'GCAAGGTGTATGAATCTGTGCT-3' (forward) and $5^{\prime}$ GTCAAGGTAACAAAGAGTGCCA-3' (reverse). Quantitative gene expression analysis was performed on the Stratagene MXPro3000 (Stratagene, San Diego, CA) with SYBR Green Master Mix (Bio-Rad). Gene expression levels were normalized to $18 \mathrm{~S}$ universal primer (Ambion Life Technology, Burlington, Canada). Dissociation curves were also acquired to test primer specificity.

\section{Western Blot Analysis}

Proteins from homogenized retinal fragments, lysed in radioimmunoprecipitation assay buffer, were quantified using Bradford's method (Bio-Rad). Protein sample $(50 \mu \mathrm{g})$ was loaded onto SDS-PAGE gel and electrotransferred onto polyvinylidene difluoride membranes. Müller cells from WT and GPR81-null mice were plated up to $80 \%$ confluency and incubated overnight in serum-free Dulbecco's modified Eagle's medium. Cells were treated with PBS or lactate $(10 \mathrm{mmol} /$ L) for 10 minutes, and the ligand binding reaction was inhibited by addition of $2 \mathrm{~mL}$ ice-cold PBS. Ice-cold radioimmunoprecipitation assay buffer $(300 \mu \mathrm{L})$ was added to lyse the cells. The cells were scraped off and agitated on a rocking platform for 30 minutes at $4{ }^{\circ} \mathrm{C}$. The lysate was further centrifuged for 30 minutes at $13,000 \times g$ at $4^{\circ} \mathrm{C}$. The supernatant was electrophoresed on $15 \%$ polyacrylamide gel for 2 hours, after which it was transferred to a polyvinylidene difluoride membrane. The membranes were immunoblotted using anti-GPR81 (SAB1300790; Sigma-Aldrich, Oakville, Canada) antibody (dilution 1:250), monoclonal anti-phosphorylated Erk1/2 (Thr202/Tyr204) antibody (dilution 1:1000; Cell Signaling, Danvers, MA), or Claudin-5 (dilution 1:300; sc-374221; Santa Cruz Biotechnology Inc., Dallas, TX). The chemiluminescence was detected with their respective secondary antibodies conjugated to horseradish peroxidase substrate (PerkinElmer, Waltham, MA). The blots were stripped and reprobed using an anti-total Erk1/2 antibody (dilution 1:1000) and an anti- $\beta$ actin monoclonal antibody (dilution 1:10,000) as a control for protein loading. The levels of Erk1/2 phosphorylation were normalized to total Erk1/2 and quantified to the ratio of phosphorylated Erk1/2/total Erk1/2 by ImageJ software. Enhanced chemiluminescence (GE Healthcare, Little Chalfont, UK) was used for detection using the ImageQuant LAS-500 (GE Healthcare).

\section{Lactate Quantification Assay}

Age-matched mice from the OIR model and control (room air) were sacrificed, and their retina was snap frozen in liquid nitrogen and stored at $-80^{\circ} \mathrm{C}$. A fragment of $50 \mathrm{mg}$ of each retina was homogenized and used to quantify tissue lactate concentration using a colorimetric assay, following manufacturer's protocol (K627; BioVision, Milpitas, CA). Readings were made on a microplate reader (EnVision Multilabel reader; PerkinElmer) adjusted for $450 \mathrm{~nm}$. Results were then converted into a concentration unit ( $\mathrm{mmol} / \mathrm{L})$ using a standard curve.

\section{Immunohistochemistry}

Müller cells were plated onto coverslips precoated with poly-D-lysine and fixed in 4\% paraformaldehyde. After blocking, cells were coincubated overnight with a rabbit anti-glutamine synthetase antibody (ab228590; Abcam, Eugene, OR; dilution 1:500) for Müller cells and an antirabbit antibody for GPR81 (SAB1300790; Sigma-Aldrich,

\footnotetext{
Figure 2 Intraretinal vascular development is delayed in GPR81 knockout (K0) mice. A: Western blot analysis showing GPR81 (39-kDa) expression in mice retinas during the second and third postnatal weeks (P8 to P21). $\beta$-Actin ( $42 \mathrm{kDa}$ ) was used as an internal control. Densitometry quantification is illustrated in the histogram. B: Representative confocal images of retinal flat mounts stained with lectin, showing superficial (red) and inner (green) vasculature in age-matched GPR81 K0 and wild-type (WT) animals collected at different postnatal days (P8, P9, and P14). Merged images show both superficial and inner vasculature networks. Dashed lines show the localization of the optic nerve. Histograms represent the quantification of the inner and superficial vasculature networks in WT versus GPR81 K0 retinas at P9 and P14. C: Delayed intraretinal vasculature in GPR81 K0 mice was corroborated on representative images of lectin-stained (green) retinal cross-sections (P9); in WT mice, abundant vasculature was detected, as highlighted by white arrows pointing to microvessels. D: Illustrations of superficial (red) and intraretinal (green) vascularization in age-matched WT and GPR81 K0 mice retina during P8, P9, and P14. Data are expressed as means \pm SEM. $n=12$ to 16 retinas per time point (B); $n=14$ to 20 retinas $(\mathbf{C}) .{ }^{*} P<0.05$ compared with P8 (using two-tailed $t$-test); ${ }^{* * P}<0.01$ compared with corresponding WT (using two-tailed test). Scale bars $=300 \mu \mathrm{m}$ (B and $\left.\mathbf{C}\right)$.
} 
Oakville, Canada; dilution 1:500). After primary antibody incubation, the cells underwent 2 hours of incubation at room temperature with a secondary antibody conjugated with Alexa Fluor (Molecular Probes, Eugene, OR). For tissue immunohistochemistry, retinas were dissected to remove cornea and lens, fixed in $4 \%$ paraformaldehyde for 1 hour, and transferred in 30\% sucrose overnight. Localization of GPR81 was determined on retina cryosections $(12 \mu \mathrm{m}$ thick). Sections were blocked with $1 \%$ bovine serum albumin, $1 \%$ goat serum, and $0.1 \%$ Triton X-100 (T-8787; Sigma-Aldrich, Oakville, Canada) in PBS and were subsequently incubated overnight with the primary antibodies. Secondary antibodies conjugated with Alexa Fluor (Molecular Probes) directed against rabbit were incubated for 2 hours at ambient temperature. Nuclei were stained with DAPI (Invitrogen; dilution 1:5000). Images were captured using $10 \times$ (for whole retina imaging) or $30 \times$ (for cells and magnified retina images) objective with an Eclipse E800 (Nikon, Melville, NY) fluorescence microscope. Whole retina images were captured using a Zeiss AxioObserver.Z1 (Zeiss, San Diego, CA). Images were merged into a single file using the MosiaX option in the AxioVision software version 4.6.5 (Zeiss, San Diego, CA).

\section{Microvascular Sprouting from Aortic Explants}

Microvascular sprouting from aortic explants was prepared from adult (1-month-old) C57BL/6J mice. Aortic rings ( $1 \mathrm{~mL}$ thick) were placed in 24-well tissue culture plates, covered with $40 \mu \mathrm{L}$ growth-factor-reduced Matrigel (BD Biosciences, San Jose, CA), and cultured for 4 days in endothelial cell growth medium-2 medium (Lonza Inc., Walkersville, MD). To establish the role of Müller cells expressing GPR81 in guiding angiogenesis, they were treated with lactate $(\mathrm{pH}$ controlled to 7.2) or vehicle and the respective conditioned medium from these cells was extracted after 24 hours to treat aortic explants. Photomicrographs of individual explants were taken over 72 hours, and microvascular sprouting was quantified by measuring the area covered by outgrowth of the aortic ring by using ImageJ software.

\section{Differentiation Assay/Tube Formation Assay}

Differentiation assays essentially measure the formation of capillary-like tubules by endothelial cells cultured on matrices consisting of fibrin, collagen, or a basement membrane substance like Matrigel that enhances the attachment, migration, and differentiation of endothelial cells into tubules in a manner analogous to the in vitro situation. Rat brain endothelial cells were plated in 24-well plates on growth-factor-reduced Matrigel and treated with lactate alone $(\mathrm{pH}$ controlled to 7.2) or incubated with conditioned medium from Müller cells and RGC-5. Images were captured using phase contrast microscopy (Eclipse TE300; Nikon), and tube formation was quantified in nonoverlapping fields with ImageJ software.
Terminal Deoxynucleotidyl Transferase-Mediated dUTP Nick-End Labeling Assay

Retinal cryosections (10 $\mu \mathrm{m}$ thick) from WT and GPR81null mice at different time points (P8, P11, and P30) were subject to the in situ cell-death detection kit (ApopTag Plus; Millipore-Sigma, Oakville, Canada) following the manufacturer's instructions. The retinal cryosections were counterstained with $0.1 \mu \mathrm{g} / \mathrm{mL}$ DAPI (Molecular Probes). Images were captured using confocal microscopy (Eclipse E800; Nikon), and the terminal deoxynucleotidyl transferase-mediated dUTP nick-end labeling-positive cells were quantified using ImageJ software.

\section{Statistical Analysis}

All data were analyzed using GraphPad Prism software version 7.0 (GraphPad Software, San Diego, CA). Normal distribution of data was tested using the Shapiro-Wilk test. ${ }^{58}$ Accordingly, parametric analysis was performed in line with the fact that power analysis is also generally greater for continuous parametric variables and given the spread of data between groups. ${ }^{59}$ Two variants were compared by $t$-test as data were normally distributed. Comparisons between several groups were performed using one-way variance analysis; Dunnett's multiple comparison method was used as a post-hoc test when many treatments were compared with one control. Descriptive statistics, including means \pm SEM, have been reported. $P<0.05$ was considered statistically significant.

\section{Results}

\section{GPR81 Receptor Is Mainly Localized in Müller Cells}

Immunohistochemistry using specific cell markers in retinal cryosections and primary isolated cell cultures revealed predominance of GPR81 in Müller cells (Figure 1, A and B). GPR81 mRNA (real-time quantitative PCR) and protein (Western blot analysis) expression on primary cell cultures or immortal cell lines corroborated the presence of GPR81 primarily on Müller cells, albeit also on RGCs, as reported, ${ }^{60}$ and (possibly) to a lesser extent on retinal pigment epithelium. However, the presence of GPR81 on endothelium was negligible (Figure 1, C and D). GPR81 antibody specificity was appreciated on Western blot analysis (Figure 1C) and by immunohistochemistry (Supplemental Figure S1) as no immunoreactivity was detected in retinas from GPR81-null mice.

\section{GPR81 Affects Intraretinal Vascular Development and Retinal Function}

GPR81 protein expression increased gradually from P8 to P12 in wild-type mice, inferring a prominent effect of GPR81 on formation of the deeper vascular network rather 


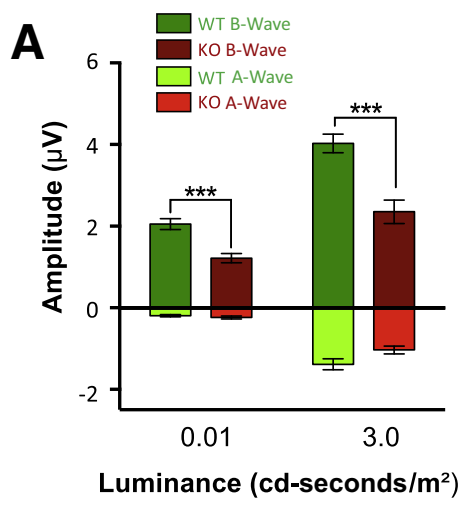

B

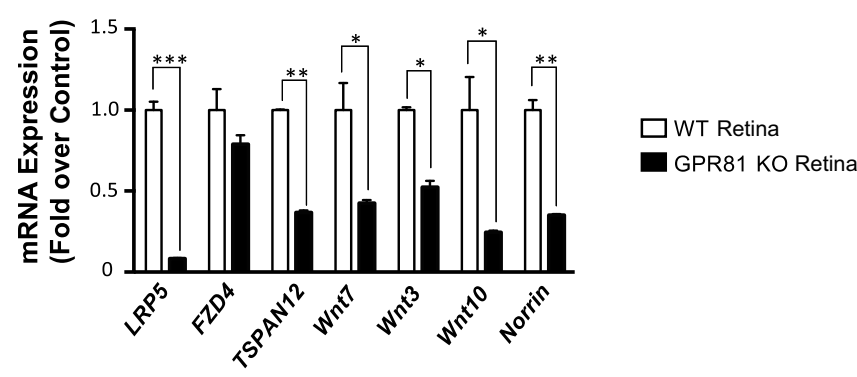

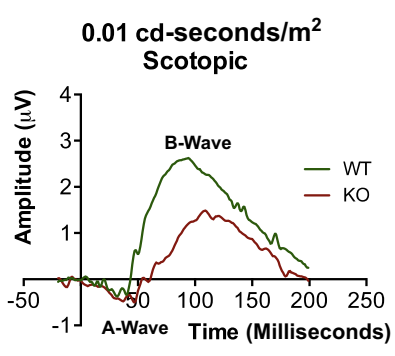

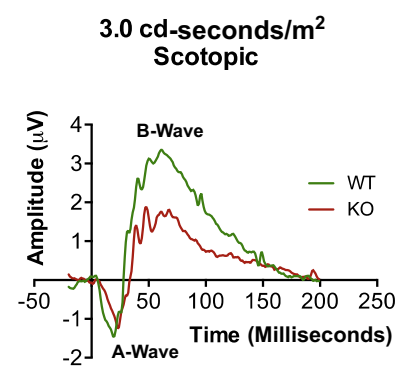

Figure 3 Delayed intraretinal vascular development results in retinal dysfunction in GPR81-null mice. A: Flash electroretinograms of age-matched wild-type (WT) and GPR81-null mice show a significant reduction in scotopic $(0.01 \mathrm{~cd}-\mathrm{sec}-$ onds $/ \mathrm{m}^{2}$ ) and photopic ( $3.0 \mathrm{~cd}$-seconds $\left./ \mathrm{m}^{2}\right)$ b-wave amplitude responses in GPR81 knockout (KO) compared with WT mice; awave amplitudes hardly differed. B: Real-time quantitative PCR analysis showing the mRNA expression of Wnt ligands and Norrin in retinas from WT and GPR81 K0 mice at P9. Data are expressed as means \pm SEM. $n=4$ to 7 eyes $(A) ; n=10$ retinas per group (B). ${ }^{*} P<0.05,{ }^{*} P<0.01$, and ${ }^{* * *} P<0.001$ compared with control values in WT mice (using two-tailed $t$-test). than intermediate network. ${ }^{61}$ By P17, GPR81 expression decreased and continued to do so by P21, at a time when the deep vascular network has been completed (Figure 2, A and B). Correspondingly, intraretinal vascularization was significantly delayed in GPR81-null mice, as shown at P8, P9, and P14 using confocal microscopy of retinal flat mounts (Figure 2B). By P14, retinal vascularization caught up and was similar in wild-type and GPR81-null mice (Figure 2B). On the other hand, GPR81 contributed modestly to the development of the superficial vasculature, as attested by comparable superficial retinal vascular development in WT and GPR81-null animals (Figure 2, $\mathrm{B}-\mathrm{D})$. Curtailed intraretinal vascular development was also observed at P9 in mice knocked down of GPR81 using a lentiviral-encoded shRNA targeting Gpr81 (Lv shGPR81) (Supplemental Figure S2, A and B), injected intravitreally in WT mice at P4 (Supplemental Figure S2C); GFP-encoding Lv exerted no effects.

A delay in vascular development is reported to likely interfere with neuroretinal function. ${ }^{62,63}$ Concordant to vascular changes, a significant number of apoptotic cells was also detected at P11 in the inner nuclear layer of GPR81-null mice during the preceding delayed vascular development (Supplemental Figure S3). Consistently, as a possible consequence of this inner nuclear cell death, ERG in these animals revealed a marked reduction (abnormality) in scotopic $\left(0.01 \mathrm{~cd}\right.$-seconds $\left./ \mathrm{m}^{2}\right)$ and photopic (3.0 cd-seconds $/ \mathrm{m}^{2}$; inner retinal function, Müller cell-contributed) b-wave amplitudes at P30 (Figure 3A); photoreceptor-generated a waves were hardly affected.
The expression of selective genes implicated in the development of the inner retinal vascular network regulated by the Wnt signaling pathway, ${ }^{23,25,64}$ such as Wnt $3 A$, Wnt7A, and Wnt10A and robustly Norrin and its coreceptors Lrp5, as well as the protein Tspan12 but not Fzd-4, were coincidentally significantly diminished in the retina of GPR81-null mice in comparison with WT mice at P9 (Figure 3B). Genes associated with the Wnt signaling pathway that play an important role in the blood-retinal barrier integrity, such as PLVAP ${ }^{65}$ and Claudin-5, ${ }^{66}$ were also altered in the GPR81-null mice at P9 (Supplemental Figure S4), consistent with their respective roles and profiles related to Norrin signaling. ${ }^{65,67}$ Overall, these findings suggest that GPR81 could be implicated in governing the expression of Norrin (and various Wnt factors) involved in inner retinal angiogenesis and blood-retinal barrier integrity during development.

\section{GPR81 Activation Accelerates Intraretinal Vascular Development}

To further establish the role of GPR81 on inner retinal angiogenesis, lactate $[10 \mathrm{mmol} / \mathrm{L}$ (final ocular concentration)] was injected intravitreally ${ }^{68,69}$ to P5 wild-type mice; this age corresponds to that of an incomplete superficial and absent deep retinal vasculature. Note that lactate binds GPR81 in the low millimolar range $\left(\mathrm{EC}_{50}=1.3\right.$ to 4.8 $\mathrm{mmol} / \mathrm{L}),{ }^{39,42}$ consistent with physiological and pathophysiological concentrations of lactate $(5$ to $20 \mathrm{mmol} / \mathrm{L}){ }^{55}$ As expected, superficial vascularization was marginally affected by lactate at P8 (when superficial vasculature is 
A

A P8 WT Vehicle
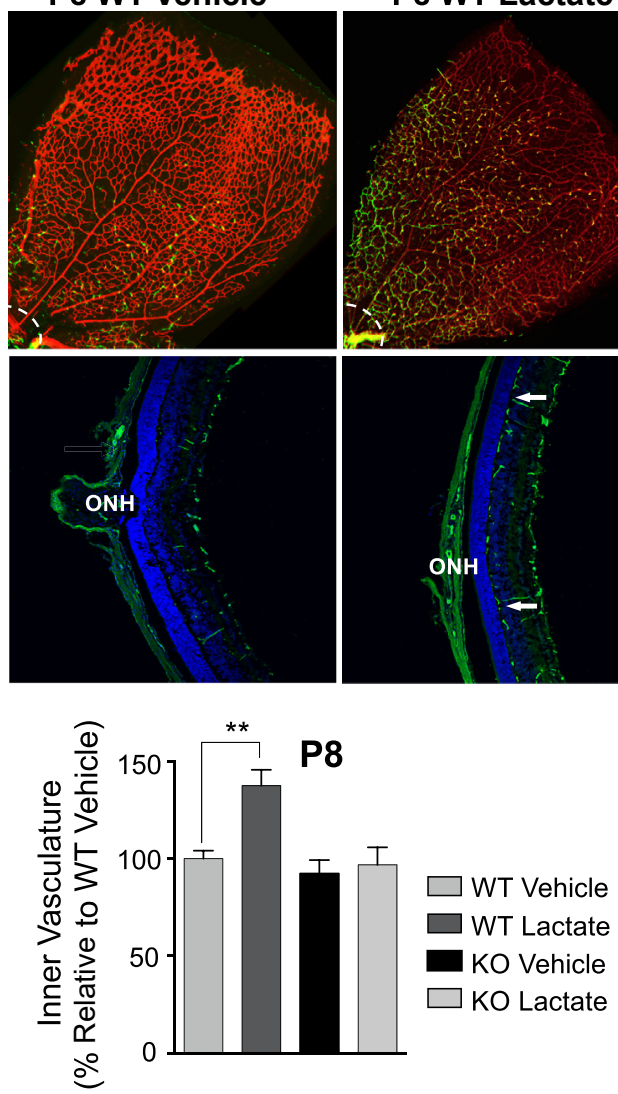

B

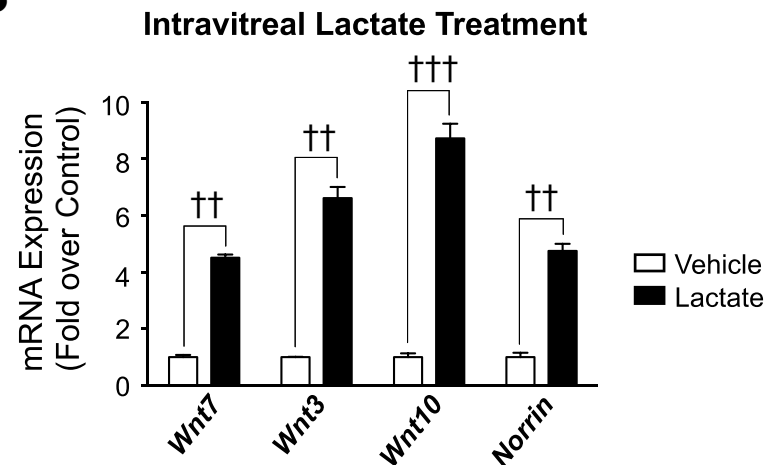

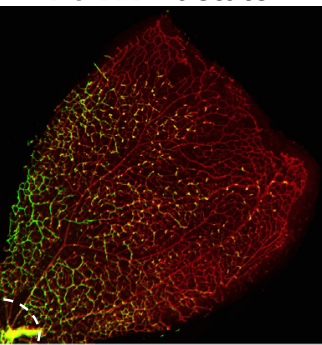

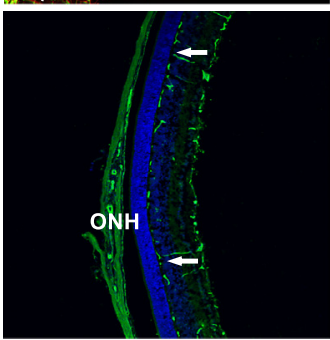

P8 KO Vehicle

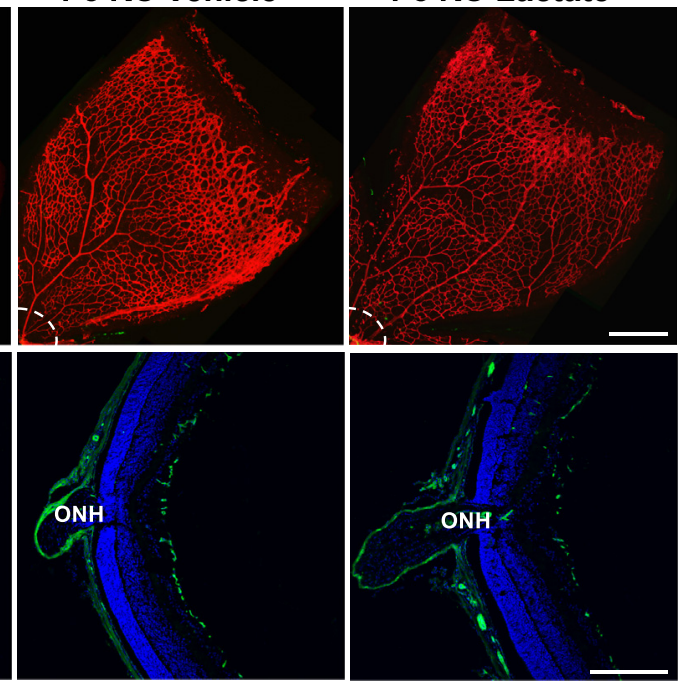

(ब)

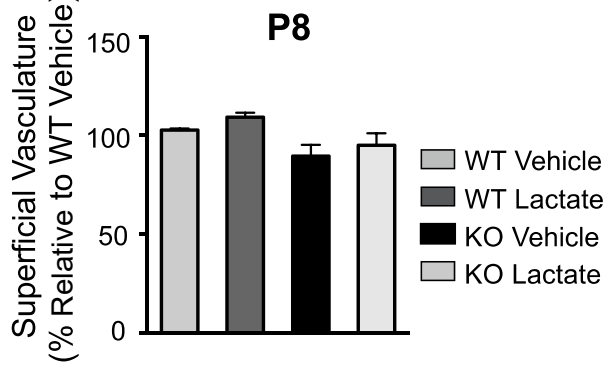

P8 KO Lactate
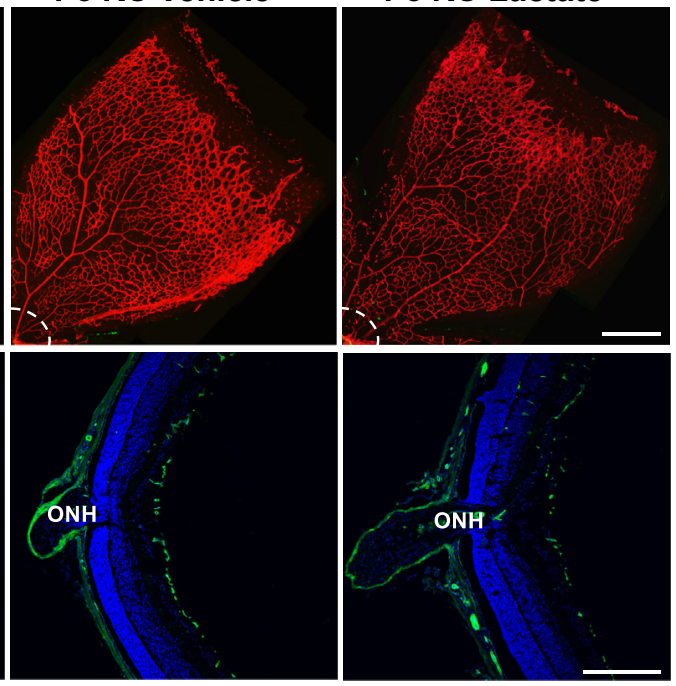

P8

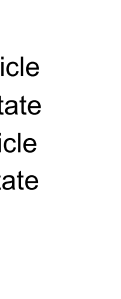

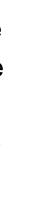


A

Wnt and Norrin Expression in Primary Müller Cells

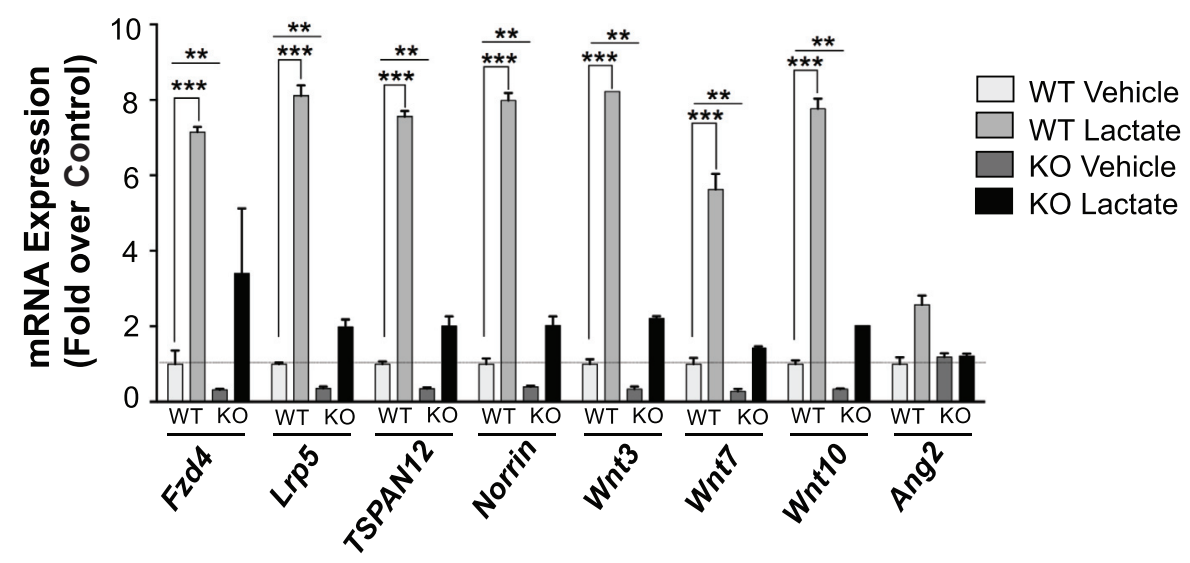

B
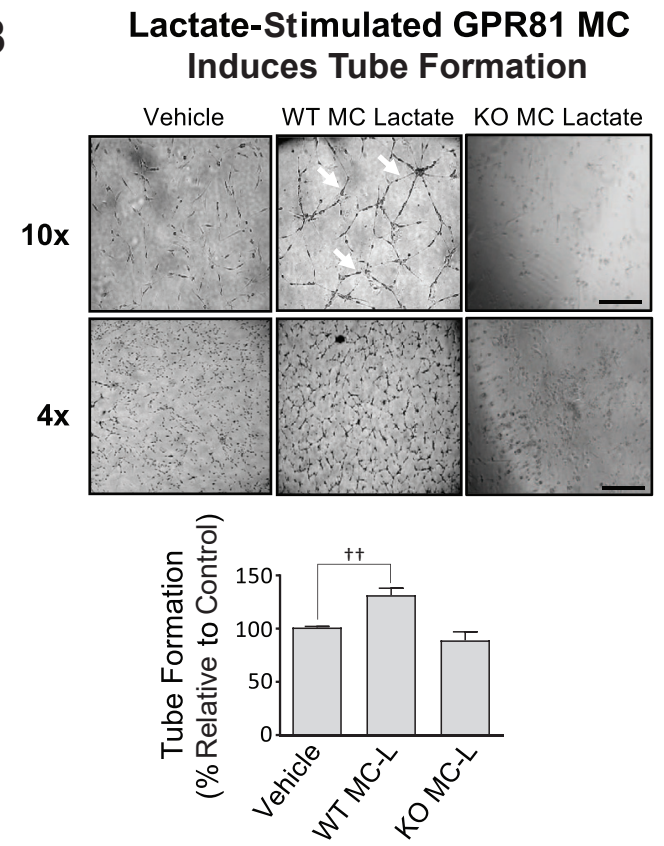

D

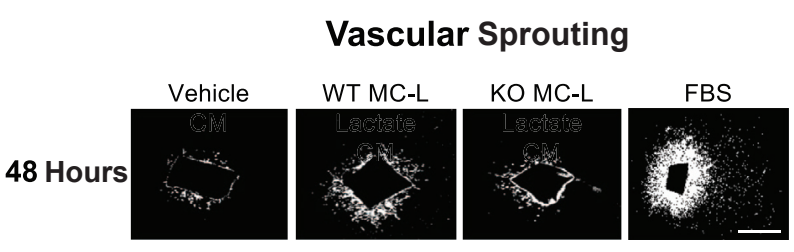

C

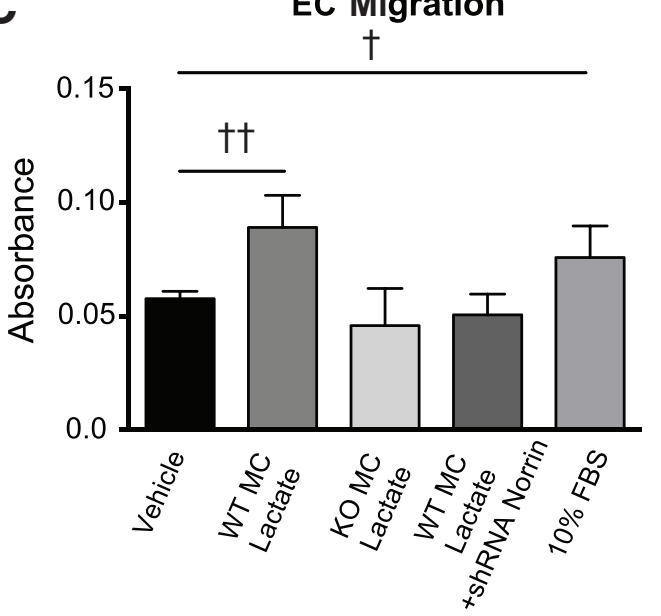

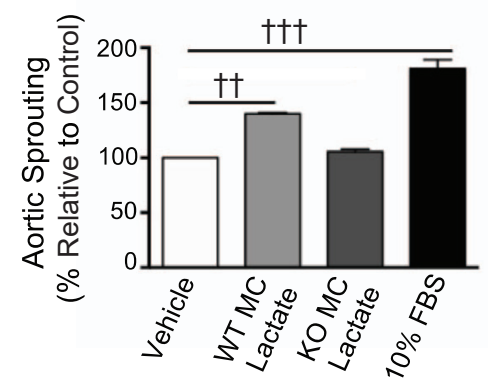

Figure 5 Proangiogenic effects of lactate acting via GPR81. A: mRNA expression, measured by real-time quantitative PCR, of lactate (10 mmol/L)-stimulated primary [wild-type (WT)] Müller cells (MCs) induced an increment in expression of Wnt ligands Wnt3A, Wnt7A, and Wnt10, and especially of Norrin but not of Ang2; this increase is not observed in primary Müller cells from GPR81 knockout (K0) mice; values are presented as fold increases over control (vehicle stimulated) and normalized for 18S. B: Representative micrographs showing endothelial cell (EC) tube formation (white arrows; measured at 24 hours after plating) induced by conditioned media from WT and GPR81 KO Müller cells previously stimulated with lactate or vehicle. Histograms show the experiments in triplicates. C: Conditioned media from WT Müller cells (MCs) stimulated with lactate (10 mmol/L) induced EC migration but not in Müller cells of GPR81 KO (KO MC) mice, and in those knocked down for Norrin (WT MC shRNA Norrin). Fetal bovine serum (FBS) was used as a positive control. Histograms represents the experiments in triplicates. D: Representative microvascular sprouting of Matrigel-embedded adult mice aortic explants treated with conditioned media from WT- and GPR81 K0 mice-derived Müller cells previously stimulated with lactate or vehicle. Histograms are the experiments in triplicates. FBS (10\%) was used as a positive control. Data were analyzed by one-way analysis of variance with Dunnett's postanalysis. Data are expressed as means \pm SEM. $n=3$ separate experiments (A-D). ${ }^{* *} P<0.01,{ }^{* * *} P<0.001$ compared with Müller cells from WT mice; ${ }^{\dagger} P<0.05,{ }^{\dagger \dagger} P<0.01$, and ${ }^{\dagger \dagger \dagger} P<0.001$ compared with corresponding control. Scale bars: 1 $\mathrm{mm}$ (B, top row, and $\mathbf{D}) ; 10 \mathrm{~mm}$ (B, bottom row). Original magnifications: $\times 10$ (B, top row); $\times 4$ (B, bottom row). MC-L, Müller cells-lactate stimulated. 

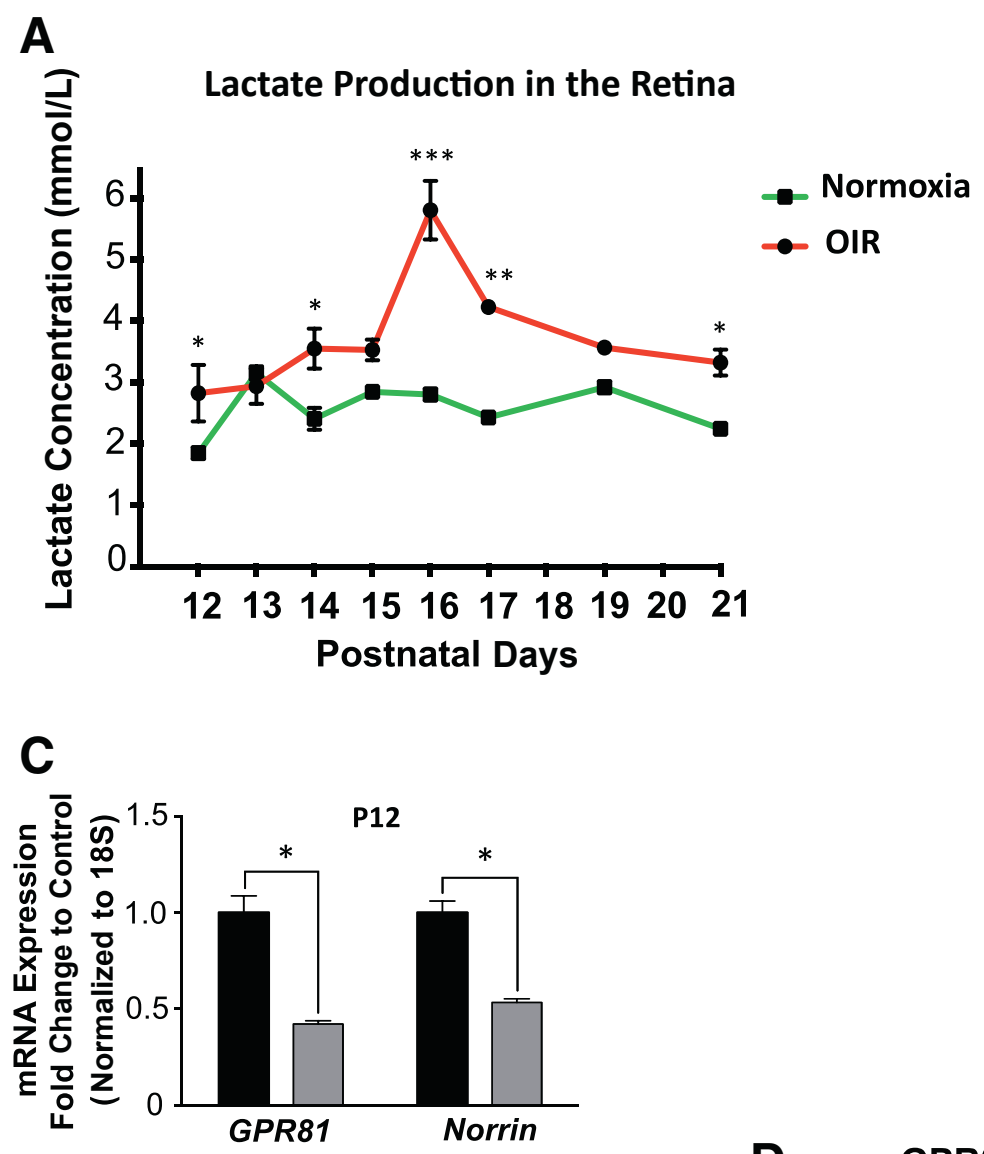

B
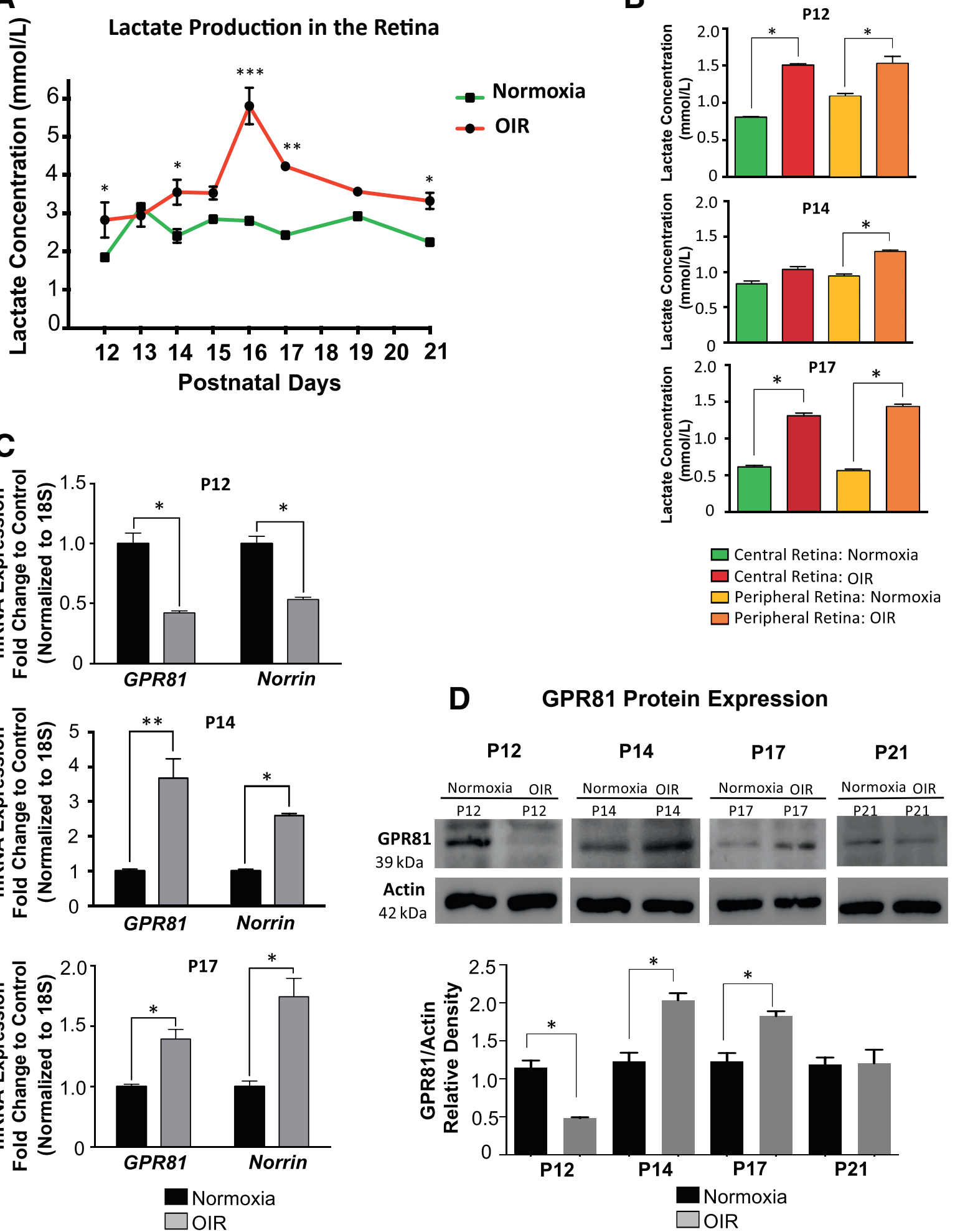

Figure 6 Increased lactate concentration in oxygen-induced retinopathy (OIR). A: Lactate concentrations (mmol/L) in retinas of wild-type mice subjected to OIR compared with normoxia-raised animals at different postnatal days. B: Lactate levels in peripheral (less ischemia) and central (more ischemia) retina of mice subjected to normoxia and OIR. C: Real-time quantitative PCR analysis showing the mRNA expression of GPR81 and Norrin at P12, P14 (midprogression of revascularization), and P17 (peaking revascularization) of mice exposed to OIR; values are presented as fold increases over control (P8) normalized to 18S. D: Western blot analysis of GPR81 (39-kDa) expression in mice retina subjected to OIR (P12 to P21) compared with normoxia-raised animals; $\beta$-actin (42 kDa) was used as an internal control. Densitometry quantification is illustrated in the histogram. Data were analyzed by one-way analysis of variance with Dunnett's postanalysis. Data are expressed as means \pm SEM. $n=14$ to 18 retinas $(\mathbf{B}) ; n=5$ to 7 retinas $(\mathbf{C}) ; n=3$ separate experiments $(\mathbf{D}) .{ }^{*} P<0.05,{ }^{* *} P<0.01$, and $* * * P<0.001$ compared with normoxia. 


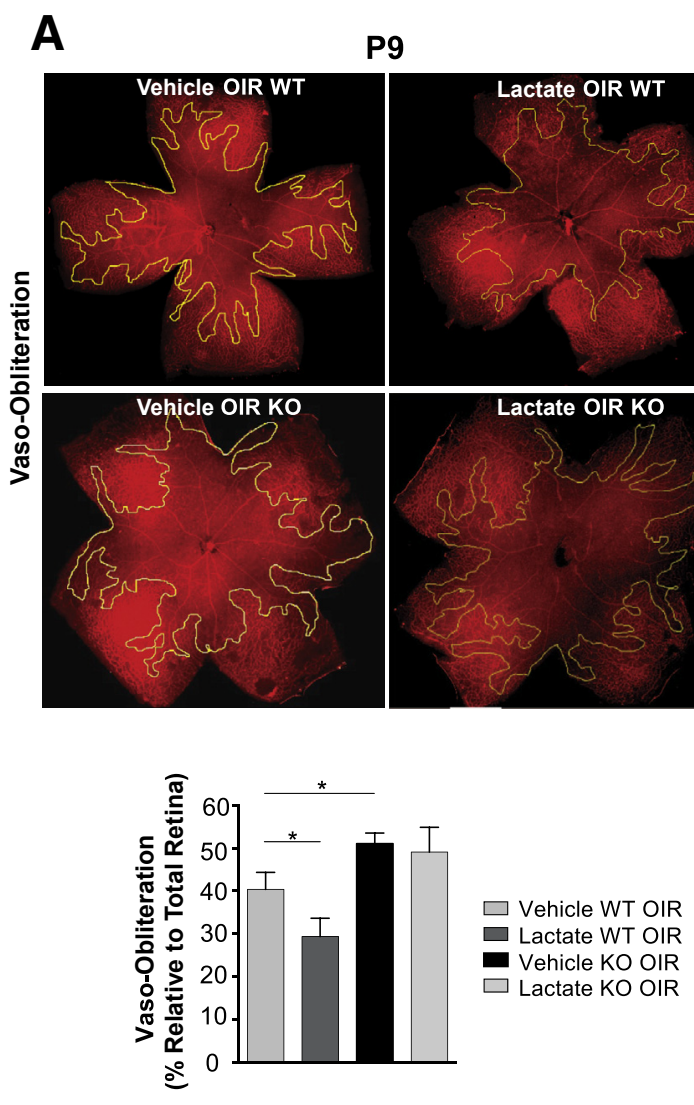

B P9

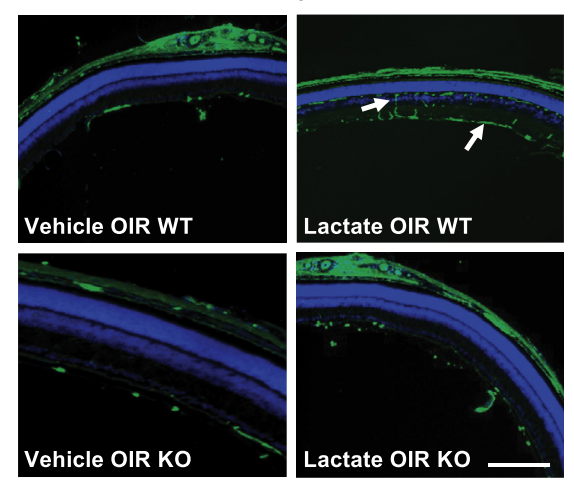

Intraretinal Vascularization

C

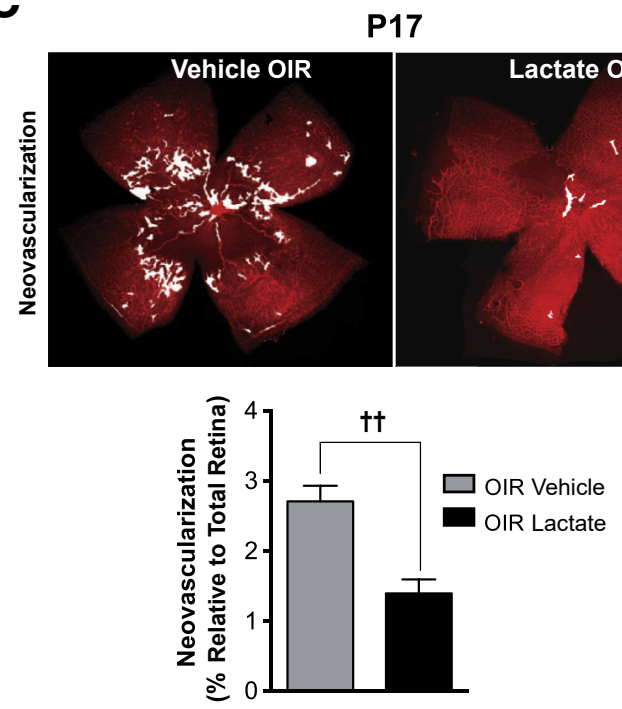

D

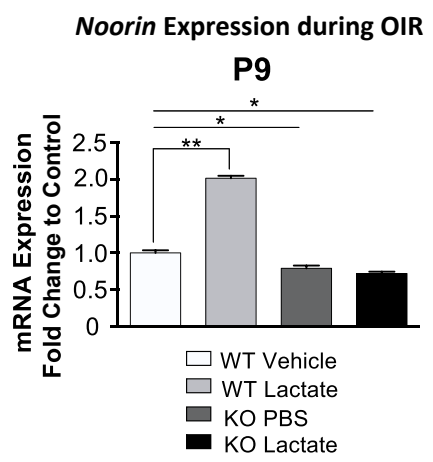

Figure 7 Lactate attenuates vaso-obliteration and consequently preretinal neovascularization in oxygen-induced retinopathy (0IR). A: Representative images from lectin-stained retinal flat mounts at P9, showing attenuation in retinal vaso-obliteration (outlined by the fine yellow line) in wild-type (WT) mice subjected to OIR retina after intravitreal injection of lactate at P7; lactate was ineffective in GPR81 knockout (K0) mice; vaso-obliteration areas are outlined with solid yellow lines. Lactate-unresponsive GPR81 K0 mice display increased vaso-obliteration. Changes in vaso-obliteration were calculated as percentage unvascularized regions relative to total retina at P9. Histogram quantification of vaso-obliteration areas is presented. B: Retinal cross-sections confirm lactateinduced stimulation of intraretinal angiogenesis (white arrows) at P9; GPR81 K0 animals were unresponsive to lactate. C: Retinal flat mounts stained with lectin showing attenuation in preretinal neovascular tufts (white areas) in lactate-treated animals subjected to OIR with respect to vehicle at P17. Histogram quantification of neovascularization is presented. D: Real-time quantitative PCR mRNA analysis of Norrin expression in retinas of WT and GPR81 K0 mice injected with vehicle or lactate during vaso-obliterative phase of OIR (P7); note increased Norrin levels at P9 in retinas injected with lactate during 0IR. Data are expressed as means \pm SEM. $n=12$ to 16 retinas (A and C); $n=6$ to 10 retinas (D). ${ }^{*} P<0.05, * * P<0.01$ compared with WT vehicle; ${ }^{\dagger \dagger} P<0.01$ compared with vehicle OIR. Scale bar $=300 \mu \mathrm{m}$ (B). PBS, phosphate-buffered saline. 

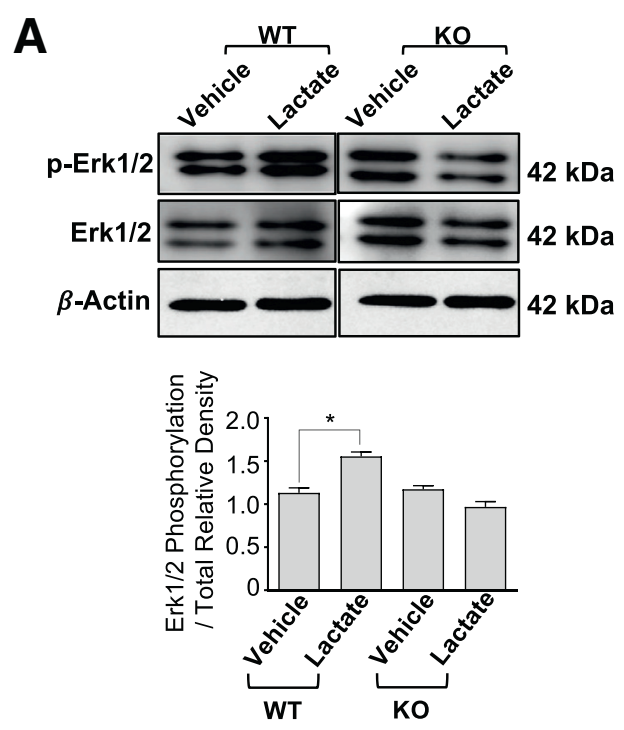

B

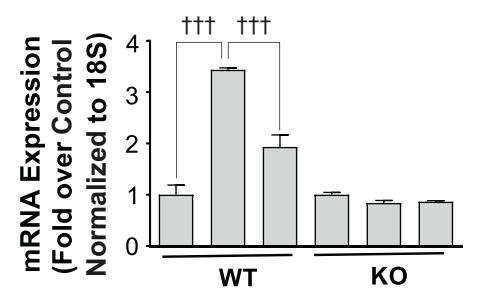

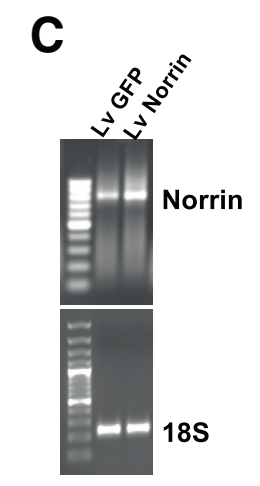

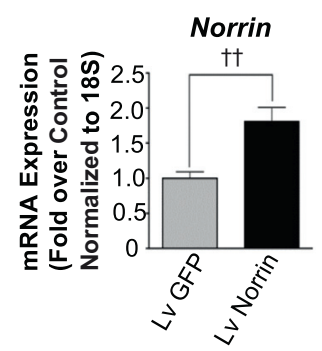

D

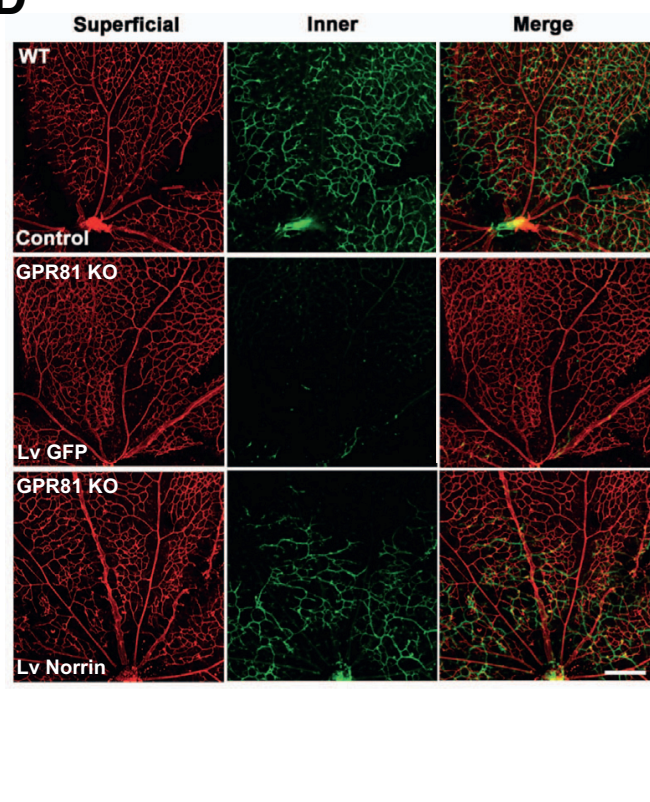

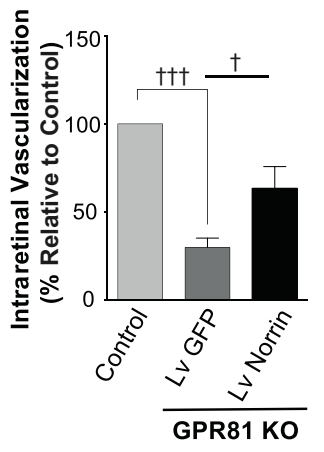

Figure 8 Norrin (up-regulation) restores intraretinal vascularization in GPR81 knockout (K0) mice. A: To investigate the mechanism of action of GPR81 via Norrin, Western blot analysis of extracellular signal-regulated kinase (Erk) 1/2 and phosphorylated Erk1/2 (p-Erk1/2) was studied in wild-type (WT) and K0 primary Müller cells. Representative images show an increase in Erk1/2 phosphorylation after lactate stimulation in Müller cells from WT mice and not in K0 Muller cells. B: mRNA expression of Norrin in WT and K0 primary Müller cells treated with or without lactate in the presence of Erk1/2-specific inhibitor (U0126). Values are presented as fold increases over control (vehicle stimulated). Data were analyzed by one-way analysis of variance with Dunnett's postanalysis. C: RT-PCR (top panel) and real-time quantitative PCR (bottom panel) confirming in vivo Norrin mRNA expression of a lentivirus (Lv) encoded with the Norrin gene (Lv Norrin) or green fluorescent protein (GFP; Lv GFP; negative control). S18 was used as internal control. D: Representative confocal images showing the superficial (red) and inner (green) retinal vasculature in WT and GPR81 K0 mice. Retinas from GPR81 K0 mice intravitreally injected with Lv Norrin increase intraretinal vascularization with respect to the mice injected with Lv GFP (negative control) at P9. Histogram quantification is presented as percentage increase in intraretinal vascularization relative to age-matched noninjected mice at starting point (set at $100 \%$ ). Data are expressed as means \pm SEM. $n=3$ separate experiments (B); $n=8$ to 12 retinas (D). ${ }^{\star} P<0.05$ quantified to the ratio of $p$-Erk1/2/total Erk1/2; ${ }^{\dagger} P<0.05,{ }^{\dagger \dagger} P<0.01$, and ${ }^{\dagger \dagger \dagger} P<0.001$ compared with control values. Scale bar $=250 \mu \mathrm{m}$ (D).

proliferation, and tube formation of endothelial cells). Conditioned medium from primary Müller cells stimulated with lactate significantly induced endothelial tube formation and migration and vascular sprouting of aortic explants
(Figure 5, B-D); lactate-stimulated Müller cells from GPR81-null mice exerted no effects. More important, Müller cells infected with a Lv containing shRNAs targeting Norrin interfered with lactate-triggered endothelial cell 
migration necessary in angiogenesis (Figure 5C). Collectively, these observations are consistent with in vivo angiogenic properties of lactate in retina and suggest that angiogenic factors, particularly Norrin, released from lactate-stimulated Müller cells, have an important contribution in retinal angiogenesis.

\section{Role of Lactate/GPR81 in Ischemic Retinopathy}

The role of lactate/GPR81 was also studied in a model of ischemic retinopathy, specifically in OIR, which mimics the two phases of ischemic retinopathy (notably, the vaso-obliteration, followed by an aberrant intravitreal neovascularization). ${ }^{48}$ Lactate levels in retina were measured at different time points during the (ischemic) vasoproliferative phase (P12 to P17) and the subsequent phase of neovascular regression (P18 to P21). Although levels of lactate in OIR-subjected animals were slightly increased at P12 (end of ischemic vaso-obliterative phase) (Figure 6A), both GPR81 and Norrin expression were low (compared with values in normoxic animals) (Figure 6, C and D). The highest values of retinal lactate were detected at P16 in the peaking revascularization phase ${ }^{71}$ (as well as in extraretinal neovascularization, which is contributed by superficial vascular metabolism ${ }^{20}$ ) when GPR81 as well as Norrin expression concomitantly increased (at P14 to P17) to restore OIR-depleted retinal vascularization, as reported ${ }^{48,49}$; thereafter, lactate levels approach basal values (by P21) along with GPR81 expression (Figure 6D), as normal vascularization is reestablished. Changes in lactate were equivalently affected at the periphery and center of the retina (Figure 6B), suggesting a marked diminution in metabolic rate of the central retina, predominantly vaso-obliterated in OIR.

\section{Lactate/GPR81 Reestablishes Norrin Expression in Ischemic Retinopathy}

The ischemic retinopathy model is initially associated with a prominent retinal vaso-obliteration detectable within 24 to 48 hours after exposure of animals to hyperoxia ${ }^{13}$ when levels of Norrin are low. ${ }^{72}$ It was, therefore, determined if exogenous lactate can attenuate retinal vaso-obliteration while reestablishing Norrin expression during ischemic retinopathy. Exposure of mice to $75 \% \mathrm{O}_{2}$ at $\mathrm{P} 7$ (to elicit OIR) led to a more marked retinal vaso-obliteration, a compromised intraretinal vascular development, and consequently predisposed to augmented preretinal neovascularization in GPR81-null mice compared with WT mice, at P17 (Supplemental Figure S5, A and B). These vascular changes in OIR coincide with timing for low expression of Norrin, critical for intraretinal vascular development. Intravitreal injection of exogenous lactate [10 $\mathrm{mmol} / \mathrm{L}$ (intraocular concentration)] in mice subjected to OIR at the beginning of the vaso-obliteration phase (at P7) increased Norrin levels in the retina at P9, reduced vaso-obliteration in WT littermates (but not in GPR81-null mice), and consequently mitigated extraretinal neovascularization (at P17) (Figure 7). These findings corroborate the angiogenic properties of lactate acting via GPR81 to stimulate not only normal retinal vascularization during development (Figure 4), but also that in OIR (Figure 7), and highlight the importance of lactate/GPR81 in regulating Norrin.

\section{GPR81 Activates Norrin via Erk1/2 Phosphorylation, and Norrin Promotes Vascular Regrowth in GPR81-Null Mice}

In view of the evidence presented herein that GPR81 governs Norrin, which, in turn, regulates intraretinal vascularization, the downstream signaling of GPR81 causing induction of Norrin was investigated. On the basis of reported information, Erk1/2 activity ${ }^{73,74}$ in primary Müller cells from WT and GPR81-null mice was studied. Phosphorylation of Erk1/2 was activated on lactate stimulation in WT but not in cells from GPR81-null animals (Figure 8A). Moreover, lactate-induced Norrin expression was significantly inhibited by the specific Erk1/2 inhibitor, U0126 (Figure 8B).

Furthermore, it was determined if Norrin can restore vascular depletion in Norrin-depleted GPR81-null mice (Figure 8, C and D). Norrin [or GFP (negative control)] gene-expressing Lv (Lv Norrin or Lv GFP) was injected intravitreally at P5, as previously reported. ${ }^{72}$ Up-regulation of Norrin was ascertained by measuring mRNA of mouse retina injected with Lv Norrin (Figure 8C) and was associated with an increase in inner retinal vascular sprouting at P9 (Figure 8D).

\section{Discussion}

Retinal microvascular degeneration and ensued tissue hypoxia in ischemic retinopathies predispose to excessive aberrant intravitreal neovascularization and defective retinal function. Prompt restoration of normal retinal vascularization in vascular depleted regions is paramount to preserve retinal integrity. ${ }^{75}$ Herein, we have discovered an unprecedented mechanism in the development of the inner retinal microvasculature. Relevant hypoxia-generated lactate and its newly described receptor GPR81 present primarily on Müller cells, govern the expression of Norrin to fulfill metabolic demands of the inner retina by stimulating vascular development, and ensure adequate oxygen supply during physiological development as well as in ischemic retinopathy. A schematic representation of our findings is depicted in Figure 9.

Traditionally, lactate was considered as a waste product of anaerobic metabolism. Lactate is now known to be a valuable intermediate metabolite implicated in several functions, including angiogenesis ${ }^{69,76,77}$; abrogation of GPR81 also reduces tumor progression and metastasis in vivo. ${ }^{78}$ Herein, we show that lactate, a biologically active molecule acting through its receptor GPR81, bridges the gap between hypoxic retina and the ensuing vascularization 


\section{OXYGEN-INDUCED RETINOPATHY}

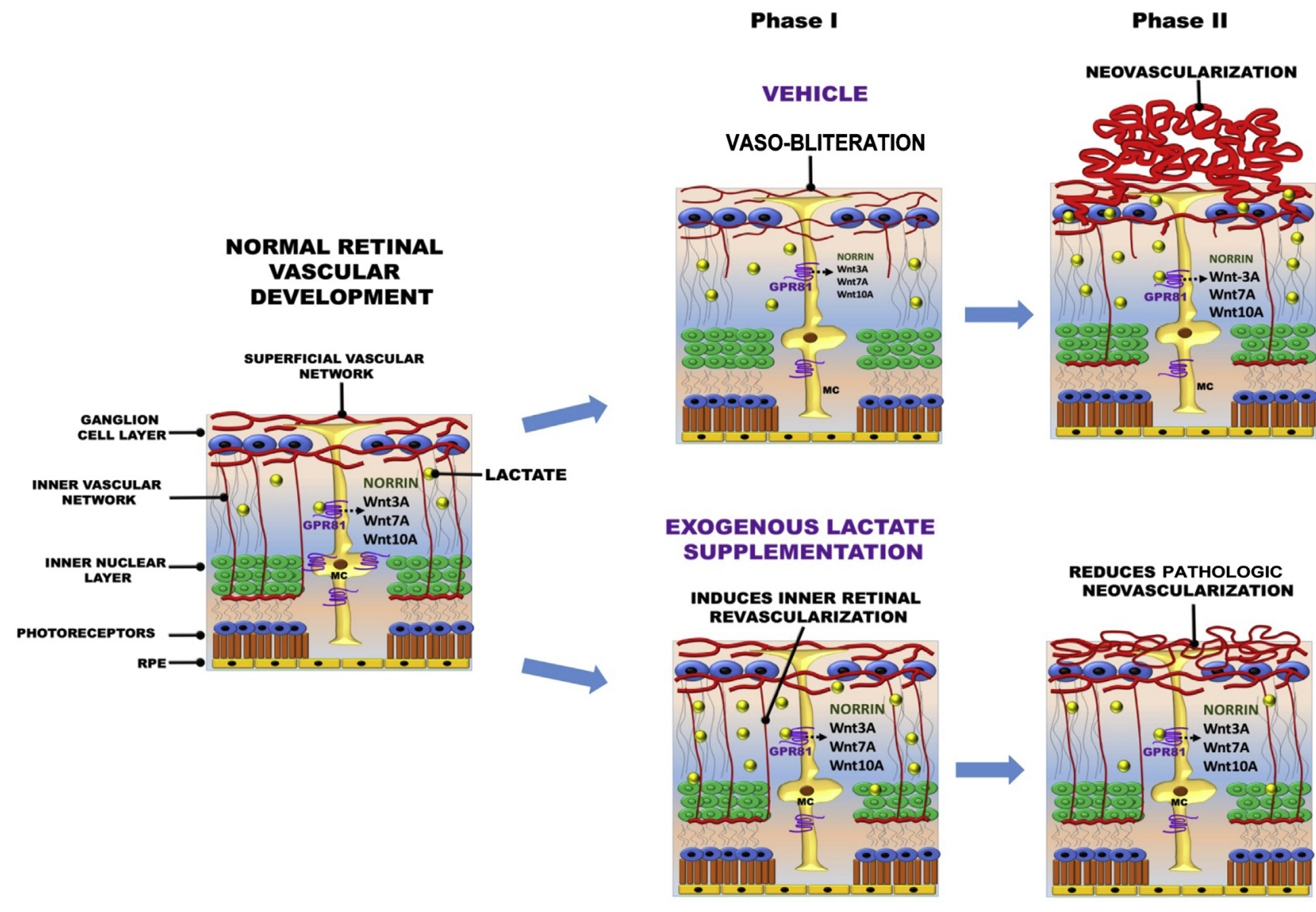

Figure 9 Illustration of mechanism of action of GPR81 in the retina. Schematic overview of lactate acting through its GPR81 receptor localized in Müller cells (MCs) governing deep intraretinal vessel formation during development and in ischemic retinopathy. Lactate/GPR81 activation stimulates expression of Wnt ligands, in particular Norrin, that act through its receptor Frizzled-4 localized on the endothelium to regulate the formation of the intraretinal vasculature during development. During the first phase in the oxygen-induced retinopathy, a progressive microvascular degeneration occurs associated with low levels of GPR81 and corresponding low levels of Norrin (regulated by GPR81). In the second phase, as an attempt to reinstate vascular supply to the hypoxic/ischemic retina, an augmentation in the production of lactate occurs. Lactate acts through increased GPR81 expression to trigger the generation of Wnt ligands (Wnt3A, Wnt7A, Wnt10A) and especially Norrin, which elicits revascularization. Conversely, down-regulation of GPR81 interferes with lactate actions in reinstating an appropriate intraretinal vascular supply, thus aggravating hypoxia and consequently preretinal neovascularization. On the other hand, administration of lactate during the vaso-obliteration phase stimulates revascularization, which accelerates the restoration of the inner retinal vasculature and subsequently decreases pathologic preretinal neovascularization. RPE, retinal pigment epithelium.

process. Lactate has been shown to exert vasoproliferative effects in tumors and skin. ${ }^{32-34}$ Of relevance, oxygen concentrations are lowest in the deep retina (inner and outer plexiform layers and inner nuclear layer), particularly before vascular development and after retinovascular injury, as in ischemic retinopathies. ${ }^{79-81}$ It was, thus, tempting to speculate that lactate (generated during hypoxia/ischemia) may act as a mediator to trigger neovascularization of the deep vascular complex in the retina. In this model of ischemic retinopathy, lactate levels started to increase at the beginning of ischemic retinopathy and reached maximum levels [comparable to those in tumors $(6$ to $15 \mathrm{mmol} / \mathrm{L})]^{82}$ before the peak pathologic neovascularization. These results suggest that lactate is implicated in rapid revascularization of affected tissue, as previously reported, ${ }^{33,34}$ but in this case specifically of the inner retinal vascular plexus, so far never described. Accordingly, exogenous lactate administered during the vaso-obliterative phase of OIR stimulates angiogenesis to promote vascular repair and, thus, reinstates metabolic supply to prevent ischemic retinopathy and ensue preretinal neovascularization. Conversely, deficiency in GPR81 accrues vaso-obliteration and, consequently, preretinal neovascularization, which seems more dependent on RGC metabolic consequences. ${ }^{20}$

An important feature of this study is that Müller cells, as classic sensors of hypoxic stress in the retina ${ }^{83}$ and major lactate secretory retinal cells, ${ }^{28,84}$ express GPR81 abundantly $^{60}$ and respond to its ligand lactate by releasing several Wnt ligands, such as Wnt3, Wnt7, Wnt10, and more important, Norrin, which is implicated in establishing 
vascular supply during physiological developmental ischemia and early in pathologic ischemic retinopathy. Notably, the Wnt ligands (Wnt3, Wnt7, and Wnt10) are angiogenic factors that play a critical role in the formation of the vascular networks during development. ${ }^{64}$ Wnt ligands have also been implicated in the development of pathologic angiogenesis during OIR. ${ }^{85}$ Hence, Wnt ligands are also likely to participate in physiological and pathologic intraretinal vascular development. Nonetheless, increased Norrin expression in GPR81-null mice was sufficient to significantly rescue intraretinal vascularization.

Müller cells, which exhibit primarily a glycolysisdependent metabolism, are the major producers of lactate in retina ${ }^{27}$; accordingly, Müller cells have the highest expression of the lactate transporter monocarboxylate transporter 1 in the retina, ${ }^{86}$ allowing its export to exert its actions on cell surface GPR81. In addition, Müller cells harbor by far the greatest expression of Norrin in retina, ${ }^{61}$ and this elongated cell, which spans the whole retina, is suitably localized to control intraretinal vascularization. This study showed a direct role for Müller cells in influencing vascular development via GPR81, as lactate stimulated Müller cells to elicit Norrin (and Wnt) expression and angiogenesis, and Norrin silencing interfered with the latter, emphasizing its importance.

Retinal angiogenesis is a complex process that involves several retinal cell types ${ }^{21,87,88}$ and, in particular, a large number of proangiogenic factors generated by neurons and glia, which have been found to govern superficial retinal vascularization. ${ }^{87,89}$ However, the factors that specifically govern the intraretinal vascular network are only now beginning to be determined. In this study, lactate was observed acting via GPR81 in governing the expression of Wnt ligands and particularly Norrin to accelerate revascularization, thereby ensuring an adequate oxygenation to the ischemic tissue. Norrin was further studied because it is a chemoattractant guiding protein almost exclusively produced by Müller cells ${ }^{61}$ that plays a critical role in the development of the intraretinal vasculature. Norrin is known to exert its vasoproliferative effects ${ }^{24}$ through the $\mathrm{Wnt} / \beta$ catenin pathway by binding to Frizzled-4, which interacts with coreceptors Lrp5 (or Lrp6) ${ }^{90}$ and Tspan12. ${ }^{24}$ Relevantly in the present context, it has also been shown that a deficiency in Norrin, Fzd-4, Lrp5/6, or Tspan12 leads to a marked deficiency in intraretinal vascular development. ${ }^{24,25,61,91}$ Consistent with these findings, it was found that although GPR81 receptor depletion hardly affected Fzd4 expression in the retina, Lrp5 and Tspan12 expression levels were decreased to a similar extent as Norrin, in line with delayed formation of the inner retinal vascular network in GPR81-null mice. More important, the activation of the GPR81 receptor by intraocular lactate stimulated Norrin expression and accelerated corresponding inner microvascular formation during retinal development in WT animals, but not in GPR81-null mice, which indicates that lactate acts via GPR81 to govern retinal angiogenesis by regulating the formation of several major angiogenic factors, including notably Norrin. Moreover, knockdown of Norrin in Müller cells interferes with endothelial cell migration, whereas rescue with Norrin of Norrin-depleted GPR81-null mice restores intraretinal vascularization. Altogether, these observations highlight the link between GPR81, Norrin, and intraretinal vascularization.

Finally, these data reveal that a deficiency in GPR81 is manifested by a depression of the b-wave amplitude, contributed by Müller cells. ${ }^{92}$ This ERG functional deficit could be attributed to the GPR81-mediated retinal cell death that occurs early during development. These deleterious effects of GPR81 deficiency, culminating in delay of inner vascular development leading to perturbed hemodynamics and retinal cell death, cannot be ignored. Conversely, lactate stimulates inner retinal vascularization as it induces Norrin expression.

All in all, we show, for the first time, that lactate exerts proangiogenic effects via GPR81 in the retina and participates in the formation of the inner retinal vascular network during development, as well as in the restoration of the vasculature in response to ischemic injury. These findings suggest lactate/GPR81 as a new potential therapeutic target to alleviate ischemic diseases.

\section{Acknowledgments}

A.M., J.C.R., and S.C. conceptualized and designed the study and prepared the manuscript; A.M. performed most of the experiments and analyzed the data; P.C., M.N.-V., R.D., C.W.H.C., and M.A.M.N. performed single blinded experiments; T.Z. designed and prepared lentivirus for G-protein-coupled receptor 81 and Norrin; J.C.R. drew the graphical illustration for Figure 8; D.H. helped troubleshoot in preliminary stages; S.P. and J.-S.J. performed electrophysiological procedures; G.M. and M.S. provided scientific advice; all authors read and approved the final manuscript.

\section{Supplemental Data}

Supplemental material for this article can be found at http://doi.org/10.1016/j.ajpath.2019.05.016.

\section{References}

1. Penn JS, Henry MM, Wall PT, Tolman BL: The range of PaO2 variation determines the severity of oxygen-induced retinopathy in newborn rats. Invest Ophthalmol Vis Sci 1995, 36:2063-2070

2. Pournaras CJ, Miller JW, Gragoudas ES, Husain D, Munoz JL, Tolentino MJ, Kuroki M, Adamis AP: Systemic hyperoxia decreases vascular endothelial growth factor gene expression in ischemic primate retina. Arch Ophthalmol 1997, 115:1553-1558

3. Pierce EA, Avery RL, Foley ED, Aiello LP, Smith LE: Vascular endothelial growth factor/vascular permeability factor expression in a mouse model of retinal neovascularization. Proc Natl Acad Sci U S A 1995, 92:905-909 
4. Pierce EA, Foley ED, Smith LE: Regulation of vascular endothelial growth factor by oxygen in a model of retinopathy of prematurity. Arch Ophthalmol 1996, 114:1219-1228

5. Pierce KL, Luttrell LM, Lefkowitz RJ: New mechanisms in heptahelical receptor signaling to mitogen activated protein kinase cascades. Oncogene 2001, 20:1532-1539

6. Ashton N: Oxygen and the growth and development of retinal vessels: in vivo and in vitro studies: the XX Francis I. Proctor Lecture. Am J Ophthalmol 1966, 62:412-435

7. Ashton N: Experimental retrolental fibroplasia. Annu Rev Med 1957 , 8:441-454

8. Luhmann UF, Lin J, Acar N, Lammel S, Feil S, Grimm C, Seeliger MW, Hammes HP, Berger W: Role of the Norrie disease pseudoglioma gene in sprouting angiogenesis during development of the retinal vasculature. Invest Ophthalmol Vis Sci 2005, 46: $3372-3382$

9. Berkowitz BA, Penn JS: Abnormal panretinal response pattern to carbogen inhalation in experimental retinopathy of prematurity. Invest Ophthalmol Vis Sci 1998, 39:840-845

10. Dorfman AL, Cuenca N, Pinilla I, Chemtob S, Lachapelle P: Immunohistochemical evidence of synaptic retraction, cytoarchitectural remodeling, and cell death in the inner retina of the rat model of oxygen-induced retinopathy (OIR). Invest Ophthalmol Vis Sci 2011, $52: 1693-1708$

11. Fulton AB, Hansen RM, Moskowitz A, Barnaby AM: Multifocal ERG in subjects with a history of retinopathy of prematurity. Doc Ophthalmol 2005, 111:7-13

12. Dobson V, Quinn GE, Abramov I, Hardy RJ, Tung B, Siatkowski RM, Phelps DL: Color vision measured with pseudoisochromatic plates at five-and-a-half years in eyes of children from the CRYO-ROP study. Invest Ophthalmol Vis Sci 1996, 37:2467-2474

13. Dorfman A, Dembinska O, Chemtob S, Lachapelle P: Early manifestations of postnatal hyperoxia on the retinal structure and function of the neonatal rat. Invest Ophthalmol Vis Sci 2008, 49: 458-466

14. Dorfman AL, Polosa A, Joly S, Chemtob S, Lachapelle P: Functional and structural changes resulting from strain differences in the rat model of oxygen-induced retinopathy. Invest Ophthalmol Vis Sci 2009, 50:2436-2450

15. Hack M, Taylor HG, Klein N, Eiben R, Schatschneider C, MercuriMinich N: School-age outcomes in children with birth weights under 750 g. N Engl J Med 1994, 331:753-759

16. Senior K: Angiogenesis and functional recovery demonstrated after minor stroke. Lancet 2001, 358:817

17. Slevin M, Kumar P, Gaffney J, Kumar S, Krupinski J: Can angiogenesis be exploited to improve stroke outcome? Mechanisms and therapeutic potential. Clin Sci (Lond) 2006, 111:171-183

18. Dembinska O, Rojas LM, Chemtob S, Lachapelle P: Evidence for a brief period of enhanced oxygen susceptibility in the rat model of oxygen-induced retinopathy. Invest Ophthalmol Vis Sci 2002, 43: $2481-2490$

19. Dembinska O, Rojas LM, Varma DR, Chemtob S, Lachapelle P: Graded contribution of retinal maturation to the development of oxygen-induced retinopathy in rats. Invest Ophthalmol Vis Sci 2001, 42:1111-1118

20. Sapieha P, Sirinyan M, Hamel D, Zaniolo K, Joyal J-S, Cho J-H, Honore J-C, Kermorvant-Duchemin E, Varma DR, Tremblay S, Leduc M, Rihakova L, Hardy P, Klein WH, Mu X, Mamer O, Lachapelle P, Di Polo A, Beausejour C, Andelfinger G, Mitchell G, Sennlaub F, Chemtob S: The succinate receptor GPR91 in neurons has a major role in retinal angiogenesis. Nat Med 2008, 14:1067-1076

21. Stone J, Itin A, Alon T, Pe'er J, Gnessin H, Chan-Ling T, Keshet E: Development of retinal vasculature is mediated by hypoxia-induced vascular endothelial growth factor (VEGF) expression by neuroglia. J Neurosci 1995, 15:4738-4747

22. Shen W, Fruttiger M, Zhu L, Chung SH, Barnett NL, Kirk JK, Lee S, Coorey NJ, Killingsworth M, Sherman LS, Gillies MC: Conditional
Muller cell ablation causes independent neuronal and vascular pathologies in a novel transgenic model. J Neurosci 2012, 32: $15715-15727$

23. Ohlmann A, Scholz M, Goldwich A, Chauhan BK, Hudl K, Ohlmann AV, Zrenner E, Berger W, Cvekl A, Seeliger MW, Tamm ER: Ectopic norrin induces growth of ocular capillaries and restores normal retinal angiogenesis in Norrie disease mutant mice. J Neurosci 2005, 25:1701-1710

24. Junge HJ, Yang S, Burton JB, Paes K, Shu X, French DM, Costa M, Rice DS, Ye W: TSPAN12 regulates retinal vascular development by promoting Norrin- but not Wnt-induced FZD4/beta-catenin signaling. Cell 2009, 139:299-311

25. Ye X, Wang Y, Cahill H, Yu M, Badea TC, Smallwood PM, Peachey NS, Nathans J: Norrin, frizzled-4, and Lrp5 signaling in endothelial cells controls a genetic program for retinal vascularization. Cell 2009, 139:285-298

26. Seitz R, Hackl S, Seibuchner T, Tamm ER, Ohlmann A: Norrin mediates neuroprotective effects on retinal ganglion cells via activation of the Wnt/beta-catenin signaling pathway and the induction of neuroprotective growth factors in Muller cells. J Neurosci 2010, 30: $5998-6010$

27. Tsacopoulos M, Poitry-Yamate CL, MacLeish PR, Poitry S: Trafficking of molecules and metabolic signals in the retina. Prog Retin Eye Res 1998, 17:429-442

28. Poitry-Yamate CL, Poitry S, Tsacopoulos M: Lactate released by Muller glial cells is metabolized by photoreceptors from mammalian retina. J Neurosci 1995, 15:5179-5191

29. Winkler BS, Arnold MJ, Brassell MA, Puro DG: Energy metabolism in human retinal Muller cells. Invest Ophthalmol Vis Sci 2000, 41: $3183-3190$

30. Albert JL, Ellington WR: Patterns of energy metabolism in the stone crab, Menippe mercenaria, during severe hypoxia and subsequent recovery. J Exp Zool 1985, 234:175-183

31. Gade G, Ellington WR: The anaerobic molluscan heart: adaptation to environmental anoxia: comparison with energy metabolism in vertebrate hearts. Comp Biochem Physiol A Comp Physiol 1983, 76 : 615-620

32. Dhup S, Dadhich RK, Porporato PE, Sonveaux P: Multiple biological activities of lactic acid in cancer: influences on tumor growth, angiogenesis and metastasis. Curr Pharm Des 2012, 18:1319-1330

33. Draoui N, Feron O: Lactate shuttles at a glance: from physiological paradigms to anti-cancer treatments. Dis Model Mech 2011, 4: $727-732$

34. Porporato PE, Payen VL, De Saedeleer CJ, Preat V, Thissen JP, Feron O, Sonveaux P: Lactate stimulates angiogenesis and accelerates the healing of superficial and ischemic wounds in mice. Angiogenesis 2012, 15:581-592

35. Brazitikos PD, Pournaras CJ, Munoz JL, Tsacopoulos M: Microinjection of L-lactate in the preretinal vitreous induces segmental vasodilation in the inner retina of miniature pigs. Invest Ophthalmol Vis Sci 1993, 34:1744-1752

36. Mason GF, Petersen KF, Lebon V, Rothman DL, Shulman GI: Increased brain monocarboxylic acid transport and utilization in type 1 diabetes. Diabetes 2006, 55:929-934

37. Schurr A, Payne RS, Miller JJ, Tseng MT, Rigor BM: Blockade of lactate transport exacerbates delayed neuronal damage in a rat model of cerebral ischemia. Brain Res 2001, 895:268-272

38. Berthet C, Lei H, Thevenet J, Gruetter R, Magistretti PJ, Hirt L: Neuroprotective role of lactate after cerebral ischemia. J Cereb Blood Flow Metab 2009, 29:1780-1789

39. Cai TQ, Ren N, Jin L, Cheng K, Kash S, Chen R, Wright SD, Taggart AK, Waters MG: Role of GPR81 in lactate-mediated reduction of adipose lipolysis. Biochem Biophys Res Commun 2008, 377:987-991

40. Davenport AP, Alexander SP, Sharman JL, Pawson AJ, Benson HE, Monaghan AE, Liew WC, Mpamhanga CP, Bonner TI, Neubig RR, Pin JP, Spedding M, Harmar AJ: International Union of Basic and 
Clinical Pharmacology: LXXXVIII: G protein-coupled receptor list: recommendations for new pairings with cognate ligands. Pharmacol Rev 2013, 65:967-986

41. Lauritzen KH, Morland C, Puchades M, Holm-Hansen S, Hagelin EM, Lauritzen F, Attramadal H, Storm-Mathisen J, Gjedde A, Bergersen LH: Lactate receptor sites link neurotransmission, neurovascular coupling, and brain energy metabolism. Cereb Cortex 2014, 24:2784-2795

42. Liu C, Wu J, Zhu J, Kuei C, Yu J, Shelton J, Sutton SW, Li X, Yun SJ, Mirzadegan T, Mazur C, Kamme F, Lovenberg TW: Lactate inhibits lipolysis in fat cells through activation of an orphan G-protein-coupled receptor, GPR81. J Biol Chem 2009, 284:2811-2822

43. Shen Z, Jiang L, Yuan Y, Deng T, Zheng YR, Zhao YY, Li WL, Wu JY, Gao JQ, Hu WW, Zhang XN, Chen Z: Inhibition of G protein-coupled receptor 81 (GPR81) protects against ischemic brain injury. CNS Neurosci Ther 2015, 21:271-279

44. Roland CL, Arumugam T, Deng D, Liu SH, Philip B, Gomez S, Burns WR, Ramachandran V, Wang H, Cruz-Monserrate Z, Logsdon CD: Cell surface lactate receptor GPR81 is crucial for cancer cell survival. Cancer Res 2014, 74:5301-5310

45. Hoque R, Farooq A, Ghani A, Gorelick F, Mehal WZ: Lactate reduces liver and pancreatic injury in Toll-like receptor- and inflammasome-mediated inflammation via GPR81-mediated suppression of innate immunity. Gastroenterology 2014, 146:1763-1774

46. Madaan A, Nadeau-Vallee M, Rivera JC, Obari D, Hou X, Sierra EM, Girard S, Olson DM, Chemtob S: Lactate produced during labor modulates uterine inflammation via GPR81 (HCA1). Am J Obstet Gynecol 2017, 216:60.e1-60.e17

47. Lee YJ, Shin KJ, Park SA, Park KS, Park S, Heo K, Seo YK, Noh DY, Ryu SH, Suh PG: G-protein-coupled receptor 81 promotes a malignant phenotype in breast cancer through angiogenic factor secretion. Oncotarget 2016, 7:70898-70911

48. Smith LE, Wesolowski E, McLellan A, Kostyk SK, D’Amato R, Sullivan R, D'Amore PA: Oxygen-induced retinopathy in the mouse. Invest Ophthalmol Vis Sci 1994, 35:101-111

49. Stahl A, Connor KM, Sapieha P, Chen J, Dennison RJ, Krah NM, Seaward MR, Willett KL, Aderman CM, Guerin KI, Hua J, Lofqvist C, Hellstrom A, Smith LE: The mouse retina as an angiogenesis model. Invest Ophthalmol Vis Sci 2010, 51:2813-2826

50. Rivera JC, Noueihed B, Madaan A, Lahaie I, Pan J, Belik J, Chemtob S: Tetrahydrobiopterin (BH4) deficiency is associated with augmented inflammation and microvascular degeneration in the retina. J Neuroinflammation 2017, 14:181

51. Sitaras N, Rivera JC, Noueihed B, Bien-Aime M, Zaniolo K, Omri S, Hamel D, Zhu T, Hardy P, Sapieha P, Joyal JS, Chemtob S: Retinal neurons curb inflammation and enhance revascularization in ischemic retinopathies via proteinase-activated receptor-2. Am J Pathol 2015, 185:581-595

52. Zudaire E, Gambardella L, Kurcz C, Vermeren S: A computational tool for quantitative analysis of vascular networks. PLoS One 2011, 6:e27385

53. Stahl A, Connor KM, Sapieha P, Willett KL, Krah NM, Dennison RJ, Chen J, Guerin KI, Smith LE: Computer-aided quantification of retinal neovascularization. Angiogenesis 2009, 12:297-301

54. Dull T, Zufferey R, Kelly M, Mandel RJ, Nguyen M, Trono D, Naldini L: A third-generation lentivirus vector with a conditional packaging system. J Virol 1998, 72:8463-8471

55. Hughson RL, Weisiger KH, Swanson GD: Blood lactate concentration increases as a continuous function in progressive exercise. J Appl Physiol (1985) 1987, 62:1975-1981

56. Wahlin KJ, Campochiaro PA, Zack DJ, Adler R: Neurotrophic factors cause activation of intracellular signaling pathways in Muller cells and other cells of the inner retina, but not photoreceptors. Invest Ophthalmol Vis Sci 2000, 41:927-936

57. Krishnamoorthy RR, Agarwal P, Prasanna G, Vopat K, Lambert W, Sheedlo HJ, Pang IH, Shade D, Wordinger RJ, Yorio T, Clark AF,
Agarwal N: Characterization of a transformed rat retinal ganglion cell line. Brain Res Mol Brain Res 2001, 86:1-12

58. Ghasemi A, Zahediasl S: Normality tests for statistical analysis: a guide for non-statisticians. Int J Endocrinol Metab 2012, 10:486-489

59. Dwivedi AK, Mallawaarachchi I, Alvarado LA: Analysis of small sample size studies using nonparametric bootstrap test with pooled resampling method. Stat Med 2017, 36:2187-2205

60. Kolko M, Vosborg F, Henriksen UL, Hasan-Olive MM, Diget EH, Vohra R, Gurubaran IR, Gjedde A, Mariga ST, Skytt DM, Utheim TP, Storm-Mathisen J, Bergersen LH: Lactate transport and receptor actions in retina: potential roles in retinal function and disease. Neurochem Res 2016, 41:1229-1236

61. Xu Q, Wang Y, Dabdoub A, Smallwood PM, Williams J, Woods C, Kelley MW, Jiang L, Tasman W, Zhang K, Nathans J: Vascular development in the retina and inner ear: control by Norrin and Frizzled4, a high-affinity ligand-receptor pair. Cell 2004, 116:883-895

62. Shin ES, Sorenson CM, Sheibani N: Diabetes and retinal vascular dysfunction. J Ophthalmic Vis Res 2014, 9:362-373

63. Reis A, Mateus C, Melo P, Figueira J, Cunha-Vaz J, Castelo-Branco M: Neuroretinal dysfunction with intact blood-retinal barrier and absent vasculopathy in type 1 diabetes. Diabetes 2014, 63:3926-3937

64. Masckauchan TN, Agalliu D, Vorontchikhina M, Ahn A, Parmalee NL, Li CM, Khoo A, Tycko B, Brown AM, Kitajewski J: Wnt5a signaling induces proliferation and survival of endothelial cells in vitro and expression of MMP-1 and Tie-2. Mol Biol Cell 2006, 17:5163-5172

65. Schafer NF, Luhmann UF, Feil S, Berger W: Differential gene expression in Ndph-knockout mice in retinal development. Invest Ophthalmol Vis Sci 2009, 50:906-916

66. Luo Y, Xiao W, Zhu X, Mao Y, Liu X, Chen X, Huang J, Tang S, Rizzolo LJ: Differential expression of claudins in retinas during normal development and the angiogenesis of oxygen-induced retinopathy. Invest Ophthalmol Vis Sci 2011, 52:7556-7564

67. Wang Y, Rattner A, Zhou Y, Williams J, Smallwood PM, Nathans J: Norrin/Frizzled4 signaling in retinal vascular development and blood brain barrier plasticity. Cell 2012, 151:1332-1344

68. Mendrinos E, Petropoulos IK, Mangioris G, Tsilimbaris MK, Papadopoulou DN, Geka A, Pournaras CJ: Vasomotor effect of intravitreal juxta-arteriolar injection of L-lactate on the retinal arterioles after acute branch retinal vein occlusion in minipigs. Invest Ophthalmol Vis Sci 2011, 52:3215-3220

69. Vegran F, Boidot R, Michiels C, Sonveaux P, Feron O: Lactate influx through the endothelial cell monocarboxylate transporter MCT1 supports an NF-kappaB/IL-8 pathway that drives tumor angiogenesis. Cancer Res 2011, 71:2550-2560

70. Ye X, Wang Y, Nathans J: The Norrin/Frizzled4 signaling pathway in retinal vascular development and disease. Trends Mol Med 2010, 16: 417-425

71. Kim CB, D'Amore PA, Connor KM: Revisiting the mouse model of oxygen-induced retinopathy. Eye Brain 2016, 8:67-79

72. Ohlmann A, Seitz R, Braunger B, Seitz D, Bosl MR, Tamm ER: Norrin promotes vascular regrowth after oxygen-induced retinal vessel loss and suppresses retinopathy in mice. J Neurosci 2010, 30: 183-193

73. Li G, Wang HQ, Wang LH, Chen RP, Liu JP: Distinct pathways of ERK1/2 activation by hydroxy-carboxylic acid receptor-1. PLoS One 2014, 9:e93041

74. Ohno Y, Oyama A, Kaneko H, Egawa T, Yokoyama S, Sugiura T, Ohira Y, Yoshioka T, Goto K: Lactate increases myotube diameter via activation of MEK/ERK pathway in C2C12 cells. Acta Physiol (Oxf) 2018, 223:e13042

75. Rivera JC, Madaan A, Zhou TE, Chemtob S: Review of the mechanisms and therapeutic avenues for retinal and choroidal vascular dysfunctions in retinopathy of prematurity. Acta Paediatr 2016, 105: $1421-1433$

76. Sonveaux P, Copetti T, De Saedeleer CJ, Vegran F, Verrax J, Kennedy KM, Moon EJ, Dhup S, Danhier P, Frerart F, Gallez B, 
Ribeiro A, Michiels C, Dewhirst MW, Feron O: Targeting the lactate transporter MCT1 in endothelial cells inhibits lactateinduced HIF-1 activation and tumor angiogenesis. PLoS One 2012, 7:e33418

77. Walenta S, Wetterling M, Lehrke M, Schwickert G, Sundfor K, Rofstad EK, Mueller-Klieser W: High lactate levels predict likelihood of metastases, tumor recurrence, and restricted patient survival in human cervical cancers. Cancer Res 2000, 60:916-921

78. Staubert C, Broom OJ, Nordstrom A: Hydroxycarboxylic acid receptors are essential for breast cancer cells to control their lipid/fatty acid metabolism. Oncotarget 2015, 6:19706-19720

79. Cringle SJ, Yu DY: Oxygen supply and consumption in the retina: implications for studies of retinopathy of prematurity. Doc Ophthalmol 2010, 120:99-109

80. Yu DY, Cringle SJ: Oxygen distribution and consumption within the retina in vascularised and avascular retinas and in animal models of retinal disease. Prog Retin Eye Res 2001, 20:175-208

81. Yu DY, Cringle SJ, Yu PK, Su EN: Intraretinal oxygen distribution and consumption during retinal artery occlusion and graded hyperoxic ventilation in the rat. Invest Ophthalmol Vis Sci 2007, 48:2290-2296

82. Hirschhaeuser F, Sattler UG, Mueller-Klieser W: Lactate: a metabolic key player in cancer. Cancer Res 2011, 71:6921-6925

83. Xin X, Rodrigues M, Umapathi M, Kashiwabuchi F, Ma T, Babapoor-Farrokhran S, Wang S, Hu J, Bhutto I, Welsbie DS, Duh EJ, Handa JT, Eberhart CG, Lutty G, Semenza GL, Montaner S, Sodhi A: Hypoxic retinal Muller cells promote vascular permeability by HIF-1dependent up-regulation of angiopoietin-like 4. Proc Natl Acad Sci U S A 2013, 110:E3425-E3434
84. Poitry-Yamate CL, Tsacopoulos M: Glucose metabolism in freshly isolated Muller glial cells from a mammalian retina. J Comp Neurol 1992, 320:257-266

85. Chen J, Stahl A, Krah NM, Seaward MR, Dennison RJ, Sapieha P, Hua J, Hatton CJ, Juan AM, Aderman CM, Willett KL, Guerin KI, Mammoto A, Campbell M, Smith LE: Wnt signaling mediates pathological vascular growth in proliferative retinopathy. Circulation 2011, 124:1871-1881

86. Gerhart DZ, Leino RL, Drewes LR: Distribution of monocarboxylate transporters MCT1 and MCT2 in rat retina. Neuroscience 1999, 92: 367-375

87. Joyal JS, Omri S, Sitaras N, Rivera JC, Sapieha P, Chemtob S: Neovascularization in retinopathy of prematurity: opposing actions of neuronal factors GPR91 and semaphorins 3A. Acta Paediatr 2012, 101:819-826

88. Hirschi KK, D'Amore PA: Control of angiogenesis by the pericyte: molecular mechanisms and significance. EXS 1997, 79:419-428

89. Sapieha P: Eyeing central neurons in vascular growth and reparative angiogenesis. Blood 2012, 120:2182-2194

90. He X, Semenov M, Tamai K, Zeng X: LDL receptor-related proteins 5 and 6 in Wnt/beta-catenin signaling: arrows point the way. Development 2004, 131:1663-1677

91. Xia CH, Liu H, Cheung D, Wang M, Cheng C, Du X, Chang B, Beutler B, Gong X: A model for familial exudative vitreoretinopathy caused by LPR5 mutations. Hum Mol Genet 2008, 17:1605-1612

92. Miller RF, Dowling JE: Intracellular responses of the Muller (glial) cells of mudpuppy retina: their relation to b-wave of the electroretinogram. J Neurophysiol 1970, 33:323-341 